\title{
The surprising role of orography in the initiation of an isolated thunderstorm in southern England
}

Article

Published Version

Lean, H. W., Roberts, N. M., Clark, P. A. and Morcrette, C. (2009) The surprising role of orography in the initiation of an isolated thunderstorm in southern England. Monthly Weather Review, 137 (9). pp. 3026-3046. ISSN 0027-0644 doi: https://doi.org/10.1175/2009MWR2743.1 Available at https://centaur.reading.ac.uk/31093/

It is advisable to refer to the publisher's version if you intend to cite from the work. See Guidance on citing.

Published version at: http://dx.doi.org/10.1175/2009MWR2743.1

To link to this article DOI: http://dx.doi.org/10.1175/2009MWR2743.1

Publisher: American Meteorological Society

All outputs in CentAUR are protected by Intellectual Property Rights law, including copyright law. Copyright and IPR is retained by the creators or other copyright holders. Terms and conditions for use of this material are defined in the End User Agreement.

www.reading.ac.uk/centaur 
Central Archive at the University of Reading

Reading's research outputs online 


\title{
The Surprising Role of Orography in the Initiation of an Isolated Thunderstorm in Southern England
}

\author{
Humphrey W. Lean, Nigel M. Roberts, Peter A. Clark, and Cyril Morcrette \\ Met Office Joint Centre for Mesoscale Meteorology, Reading, and Met Office, Exeter, United Kingdom
}

(Manuscript received 31 July 2008, in final form 16 February 2009)

\begin{abstract}
Many factors, both mesoscale and larger scale, often come together in order for a particular convective initiation to take place. The authors describe a modeling study of a case from the Convective Storms Initiation Project (CSIP) in which a single thunderstorm formed behind a front in the southern United Kingdom. The key features of the case were a tongue of low-level high $\theta_{w}$ air associated with a forward-sloping split front (overrunning lower $\theta_{w}$ air above), a convergence line, and a "lid" of high static stability air, which the shower was initially constrained below but later broke through. In this paper, the authors analyze the initiation of the storm, which can be traced back to a region of high ground (Dartmoor) at around 0700 UTC, in more detail using model sensitivity studies with the Met Office Unified Model (MetUM). It is established that the convergence line was initially caused by roughness effects but had a significant thermal component later. Dartmoor had a key role in the development of the thunderstorm. A period of asymmetric flow over the high ground, with stronger low-level descent in the lee, led to a hole in a layer of low-level clouds downstream. The surface solar heating through this hole, in combination with the tongue of low-level high $\theta_{w}$ air associated with the front, caused the shower to initiate with sufficient lifting to enable it later to break through the lid.
\end{abstract}

\section{Introduction}

Forecasting convective precipitation is of great practical importance. The impact of flash flooding from convective storms can be very serious in the United Kingdom (Collier 2007). For example, the flash flooding in Boscastle, a village on the north Cornwall coast in the southwest peninsula of England, on 16 August 2004 (Burt 2005; Golding et al. 2005), in which over $150 \mathrm{~mm}$ of rain fell into a small river catchment (less than $10 \mathrm{~km}^{2}$ ), lead to the destruction of buildings and the emergency rescue of many people. A study of U.K. extreme rainfall events identified a number of convectively driven, short-period events of similar importance (Hand et al. 2004).

The Met Office, in common with other forecasting centers, is therefore moving toward high-resolution NWP models for short-range forecasting of precipitation. There have been a number of studies of the representation and prediction of convection in kilometer-scale nu-

Corresponding author address: Humphrey Lean, Met Office JCMM, Meteorology Building, University of Reading, Reading, RG6 6BB, United Kingdom.

E-mail: humphrey.lean@metoffice.gov.uk merical models (Weisman et al. 1997; Romero et al. 2001; Done et al. 2004; Lean et al. 2008; Roberts and Lean 2008; Schwartz et al. 2009). A key problem is to be able to predict convective initiation (CI) accurately. This will only be possible if a model correctly represents the factors that contributed to the CI. Understanding these may require extensive analysis and research. Bennett et al. (2006) presented a review of CI in the United Kingdom. They also highlighted that very little observational work on initiation had been carried out in the United Kingdom.

The Convective Storms Initiation Project (CSIP; Browning et al. 2007), made observations during the initiation and development of precipitating convection over southern England in the summer of 2005. A key aim of CSIP is to improve numerical models by making comparisons between the observations and NWP-model simulations of the intensive observations periods (IOPs). This paper presents work on CSIP IOP1, which was also the subject of an earlier observational paper by Morcrette et al. (2007, hereafter M07). We present a series of model experiments designed to elucidate the processes that came together to cause the initiation of an isolated thunderstorm over southern England. Section 2 presents an overview of the case and further 

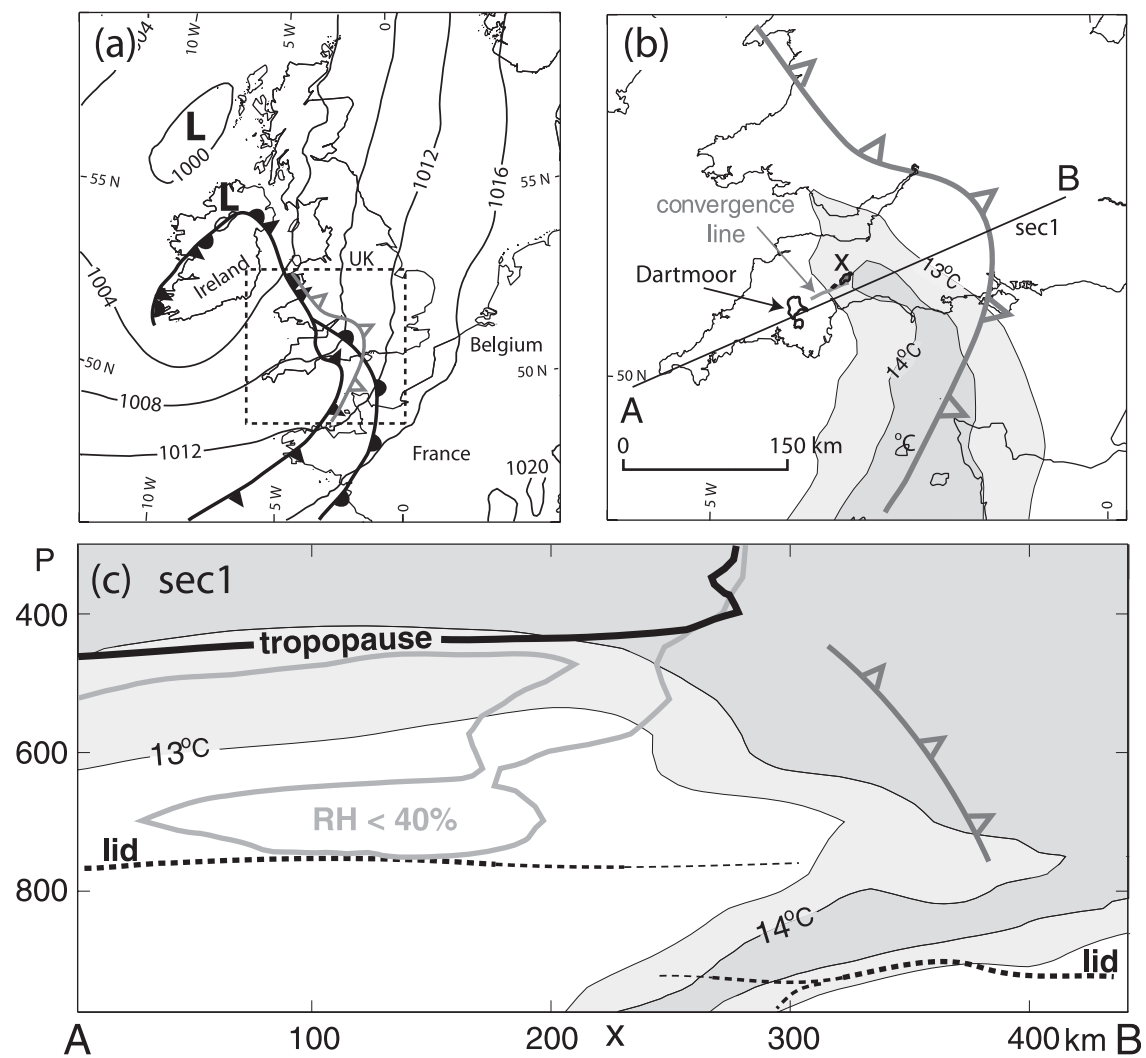

FIG. 1. (a) Synoptic analysis showing mean sea level pressure, surface fronts (black), and upper front (gray). Dashed box shows area shown in (b). (b) Analysis of low-level $\theta_{w}$ (shading) at $975 \mathrm{hPa}$ and upper-level front. The low-level convergence line is marked with a gray line. Shower is marked in dark gray from the $1.5-\mathrm{km}$ model and labeled X. (c) Cross section through analysis along line $\mathrm{A}-\mathrm{B}$ in (a). The $\mathrm{X}$ shows position of shower tangential to cross section. All are at 0800 UTC based on 12-km model.

motivates the work. Section 3 describes the model and its configuration used in this study. Section 4 discusses the origin of the convergence line inferred by M07 as contributing to the initiation of the shower. Section 5 discusses why only a single storm formed and the role of the orography. Section 6 discusses the combination of mechanisms leading to $\mathrm{CI}$ and the overall conclusions are summarized in section 7 .

\section{Overview of case and motivation for study}

IOP1 of CSIP has been described by M07. Large-scale and upper-level aspects have also been discussed by Russell et al. (2008). Showers formed behind a frontal system that moved eastward across the southern United Kingdom on the morning of 15 June 2005. Of particular interest is that just one shower deepened to become an isolated thunderstorm, reaching a reflectivity of $52 \mathrm{dBZ}$ implying rain rates up to $60 \mathrm{~mm} \mathrm{~h}^{-1}$. A schematic analysis of the situation at 0800 UTC is shown in Fig. 1 (similar to that shown in M07 for 1100 UTC). This is based on an 8-h 12-km model forecast from the operational 0000 UTC 12-km analysis. We will not repeat the comparison with observations of M07, but they do show that the $12-\mathrm{km}$ forecast agrees well with available observations, and the success of the $1.5-\mathrm{km}$ grid-length forecast driven from it gives us further confidence in its accuracy.

The main elements identified by M07 are the following:

1) A forward-sloping tongue of low-level air with relatively high wet bulb potential temperature $\left(\theta_{w}\right)$ with overrunning low $\theta_{w}$ air above. This is a split-front structure similar to those described by Browning and Monk (1982) and Browning and Roberts (1996).

2) A low-level convergence line, which is approximately along the axis of the U.K. southwest peninsula.

3) A "lid" of high static stability (in potential temperature, $\theta$ ) at around $700 \mathrm{hPa}$ with the lower $\theta_{w}$ air above this lid and the higher $\theta_{w}$ air below.

The low-level high $\theta_{w}$ tongue with overrunning lower $\theta_{w}$ air creates potential instability. The shower that became the thunderstorm was located at the intersection 

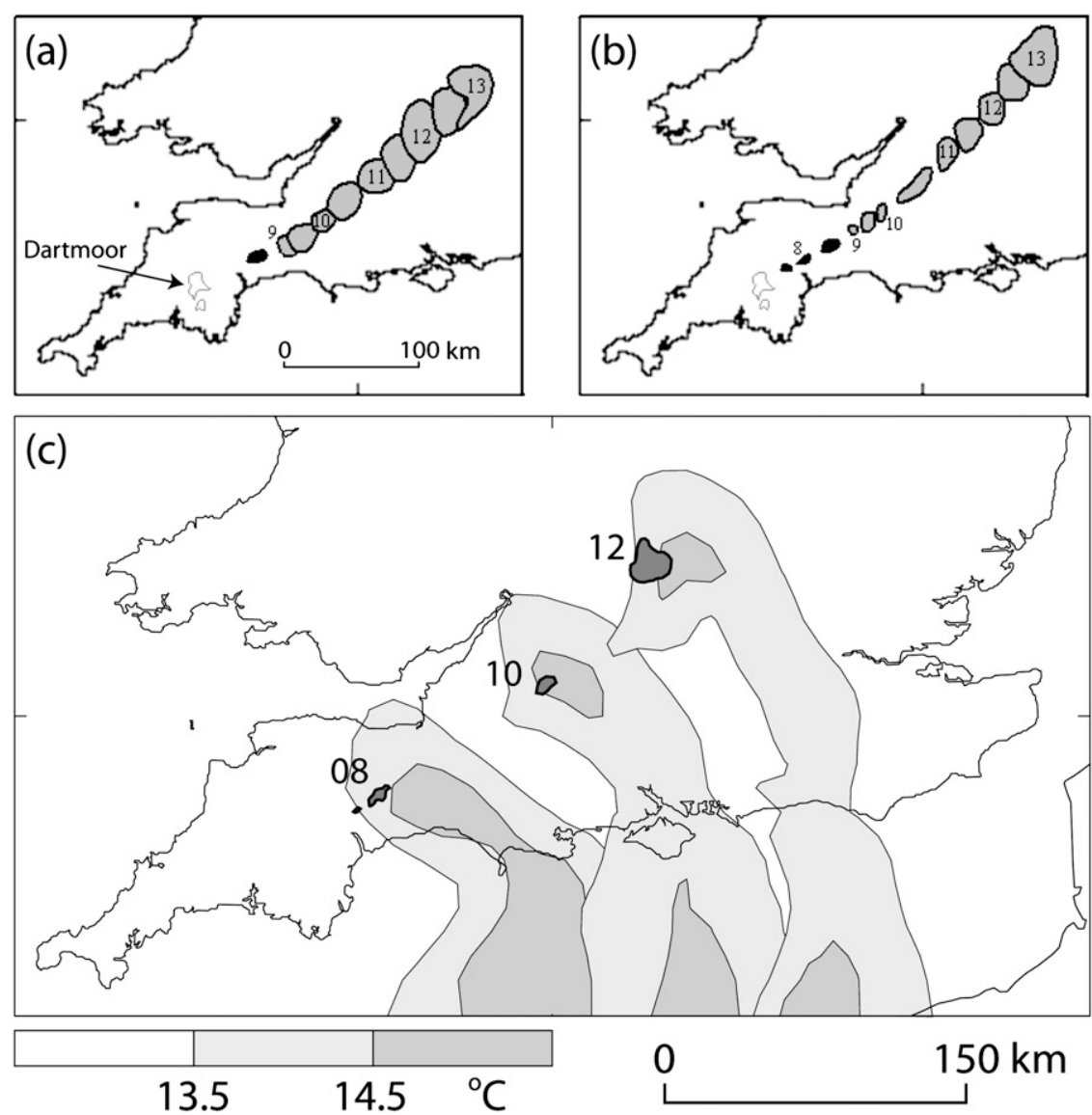

FIG. 2. Position of main shower at half-hour intervals in (a) observations and (b) $1.5-\mathrm{km}$ model. Numbers indicate positions at respective times (UTC). Gray shaded areas are location of precipitation (from radar in observation plot) black areas are clouds (from visible imagery in observation plot). The contour shown is at $400 \mathrm{~m}$ to locate the highest parts of Dartmoor. (c) The location of high $975-\mathrm{hPa} q_{w}$ tongue at $2 \mathrm{~h}$ intervals (gray shades). The dark areas show the locations of the deepest showers (found by regions where the lid is elevated).

of the high $\theta_{w}$ tongue with the convergence line. The shower first appeared on the network radar at about 0900 UTC (Fig. 2a) but did not deepen significantly for a couple of hours until it broke through the $700-\mathrm{hPa}$ lid at around 1100 UTC (note that for the U.K. local solar time is approximately the same as UTC). Figure 2 shows that the cloud, which was a precursor of the shower, can be traced back to the region just downstream of Dartmoor (an area of high ground in southwest England) at around 0800 UTC (the cloud can be traced back a little earlier and farther upstream in the observations than in the model). This is the time when the low level-warm tongue has just crossed the area (Figs. 1a and 2c).

The focus of M07 was on the observations of how the large shower deepened from being shallow by breaking through a lid of high static stability air at around $700 \mathrm{hPa}$. The observations were also shown to compare well to a 1.5-km grid-length run of the Met Office Unified Model (MetUM). Unanswered questions from that study include why only one cloud deepened to become a heavy shower while others did not. This question is less amenable to investigation with the CSIP observations since the initiation took place to the southwest, outside the main CSIP area (see M07).

In this paper we use model experiments to investigate the mechanisms of formation of the convergence line and for the initiation of the original shower that eventually deepened into the thunderstorm of interest.

\section{Description of model}

The model used in this work was the nonhydrostatic version of the MetUM (Davies et al. 2005). This solves nonhydrostatic, deep-atmosphere dynamics using a semiimplicit, semi-Lagrangian numerical scheme (Cullen 
et al. 1997; Davies et al. 2005) on a rotated latitudelongitude horizontal grid with Arakawa C staggering and a terrain-following hybrid-height vertical coordinate with Charney-Philips staggering. It includes a comprehensive set of parameterizations, including subsurface and surface fluxes (Essery et al. 2001), boundary layer turbulence (Lock et al. 2000), and mixed-phase cloud microphysics (Wilson and Ballard 1999) with enhancements to include more hydrometeor species. It also contains a convection parameterization [Gregory and Rowntree (1990), with additional downdraft and momentum transport parameterizations], but this is switched off in the $1.5-\mathrm{km}$ model.

The configuration used in the current study was similar to that described in Lean et al. (2008) except that the $1-\mathrm{km}$ grid-length model was replaced by a $1.5-\mathrm{km}$ one in order to allow a greater area to be covered. The domains are shown in Fig. 3. Each stage used one-way nesting; lateral boundary conditions for the $1.5-\mathrm{km}$ model were provided by a $4-\mathrm{km}$ model that was driven by boundary conditions from the operational $12-\mathrm{km}$ model. It was important that the whole of the southwest peninsula was included in the $1.5-\mathrm{km}$ model domain. The 4-km model was kept on the same domain as that used previously (Lean et al. 2008) even though it meant that the northern $1.5-\mathrm{km}$ model boundary was very close to the boundary of the 4-km model. This was not problematic in this case since it was an outflow boundary (and this was an experimental configuration that was not used routinely for other cases). The $4-$ and $1.5-\mathrm{km}$ models were run starting from a $T+1$ state from the $12-\mathrm{km} 0000$ UTC operational run, allowing a sufficiently long forecast period to ensure that any "spinup" problems were dissipated (see Lean et al. 2008 for discussion of spinup issues) by 0700 UTC after which the shower initiated. The high-resolution models were run without any additional data assimilation. As described in more detail by Lean et al. (2008) the most important differences between the 12-, 4-, and $1.5-\mathrm{km}$ models was in the convective parameterization. The $12-\mathrm{km}$ model was run with the standard convection scheme, the 4-km used the same scheme but with the mass flux limited as a function of CAPE (Roberts 2003). The 1.5-km had no convective parameterization.

The standard $1.5-\mathrm{km}$ model run starting 0100 UTC from 0000 UTC data represented the development of the storm well (Figs. 2 and 4). The general location and the timing of the storm is good but the model produces a storm that is somewhat smaller and more intense (a known problem with the $1.5-\mathrm{km}$ model; Lean et al. 2008) and propagates a little too fast. Because the shower initiated in the model during the run we assume that the the key features of the CI were successfully

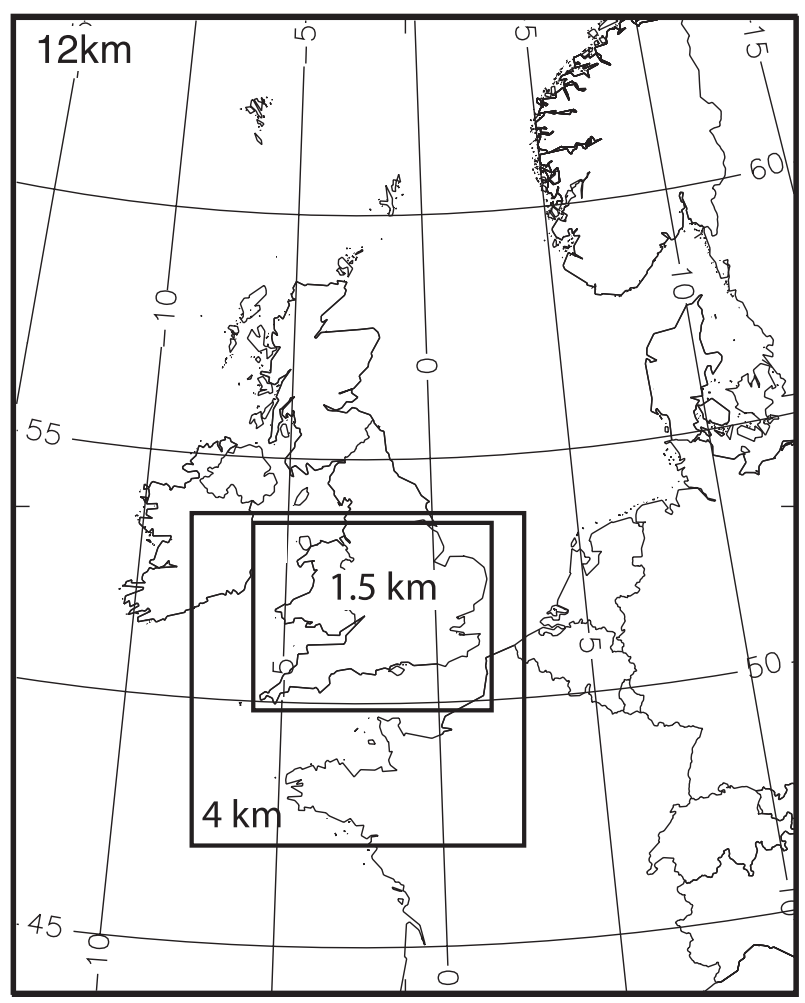

FIG. 3. Domains of models used in study.

captured. Therefore, we hope to gain insight into the mesoscale features that led to the development of the convergence line and the factors that led to the initiation of the shower.

\section{Origin of the convergence line and its influence on initiation}

The analysis in section 2 states that the convergence line is important in the initiation and development of the storm. It is well known that boundary layer convergence lines can be important in the initiation of thunderstorms (e.g., Purdom 1976; Wilson et al. 1992; Bennett et al. 2006). In this section we test that hypothesis for this particular case and investigate the origin of the convergence line by running modified model simulations. Three possible causes of the convergence line have been tested: orography, diurnal heating, and land-sea roughness contrast.

To test these hypotheses we have rerun the $1.5-\mathrm{km}$ model with (separately) the orography removed, the solar heating removed, and with land surface roughness reduced by a factor of 100 , comparable with, though a little higher than, that over the sea. Sea surface roughness varies with surface wind speed following a generalization of the Charnock formula (Smith 1988). 


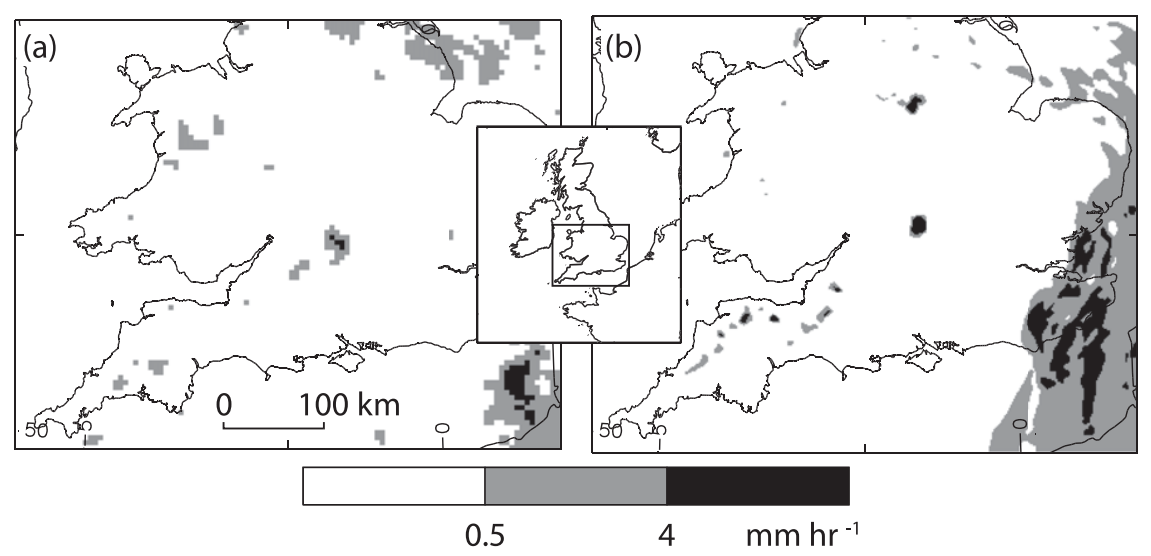

FIG. 4. Comparison of rain rate $\left(\mathrm{mm} \mathrm{h}^{-1}\right)$ at 1200 UTC (a) from radar and (b) from the $1.5-\mathrm{km}$ model. The radar data is shown on a $5-\mathrm{km}$ grid and the model data is on the raw $(1.5 \mathrm{~km})$ grid. The area shown is the full domain of the $1.5-\mathrm{km}$ model and the inset serves to locate this.

At this point it is worth summarizing the general boundary layer development behind the front. The flow over the sea is generally weakly stable, as would be expected with a relatively strong wind from the southwest. Before 0600 UTC the land boundary layer is stably stratified at the surface. The passage of the front left the surface moist, and this is reflected in positive latent heat fluxes over land behind the front. Between 0600 and 0700 UTC surface heat fluxes become positive over land and a shallow unstable boundary layer starts to grow and deepen. However, a large proportion (initially up to $90 \%$ and declining to $60 \%$ by 0900 UTC) of the surface turbulent heat flux goes into the upward latent heat flux. The model boundary layer diagnostics indicate that the boundary layer mixing extended into the layer cloud, which formed by 0700 UTC.

Figure 5a shows the low-level $(925 \mathrm{hPa})$ vertical velocity from the standard run at 0700 UTC. This corresponds closely in pattern to the surface convergence (not shown) but is less contaminated by very small-scale orography. The early stage of the convergence line of interest can be seen to the west of Dartmoor along with some ascent along the upslope. The line stops near the peak of Dartmoor. Closer analysis shows that, while Dartmoor disrupts the line, it is present downstream shortly after this time. Figure $5 \mathrm{~b}$ shows a rerun with the model orography set to zero everywhere. The convergence is still present in this case although it is somewhat different and, in the absence of Dartmoor, continues farther downstream. Thus, it is apparent that the orography is not essential for the formation of the convergence line. Figure $5 \mathrm{c}$ shows a rerun with the incoming solar radiation turned off. The vertical velocity field looks very similar to that in the standard run, showing that solar radiation is not a factor at this time. In par- ticular, the convergence line is not a sea-breeze convergence line driven by surface-heating induced pressure gradients between land and sea. This is not a surprise given that even in summer it is unlikely that there will have been sufficient surface heating by 0700 UTC to generate a sea-breeze axis far inland.

Figure $5 \mathrm{~d}$ shows the rerun where the surface roughness over land has been reduced by a factor of 100 . The convergence line is no longer present (although the upslopeascent remains). We conclude that the initial formation of the convergence line is primarily driven by roughness effects. The mechanism is essentially a coastal convergence effect as discussed by Roeloffzen et al. (1986), though it is likely that the stable lid also contributed to the dynamics (Hunt et al. 2004). Later in the day, multiple convergence lines formed and, while they could possibly be traced back to individual promontories on the upstream coast, they also formed a fairly regular spacing, suggesting that they formed a system of boundary layer rolls. The convergence line of interest, however, formed as a single, distinct line well before this and should not be considered as a part of boundary layer roll system.

Figures 6a,b shows the vertical velocity fields from the standard and reduced-roughness runs at 0800 UTC. By this time the main convergence line has moved downstream of Dartmoor in the standard run. Closer examination suggests two convergence lines are formed starting near the tip of the southwest peninsula, one associated with the north coast, one with the south, growing downstream and leaving the coast. This is very similar to the coastal convergence lines predicted by Hunt et al. (2004) for surface flows capped by a stable layer. In the run with reduced roughness there are signs of a weak convergence line appearing approximately along the axis of the peninsula. Figure $6 \mathrm{c}$ shows a run 

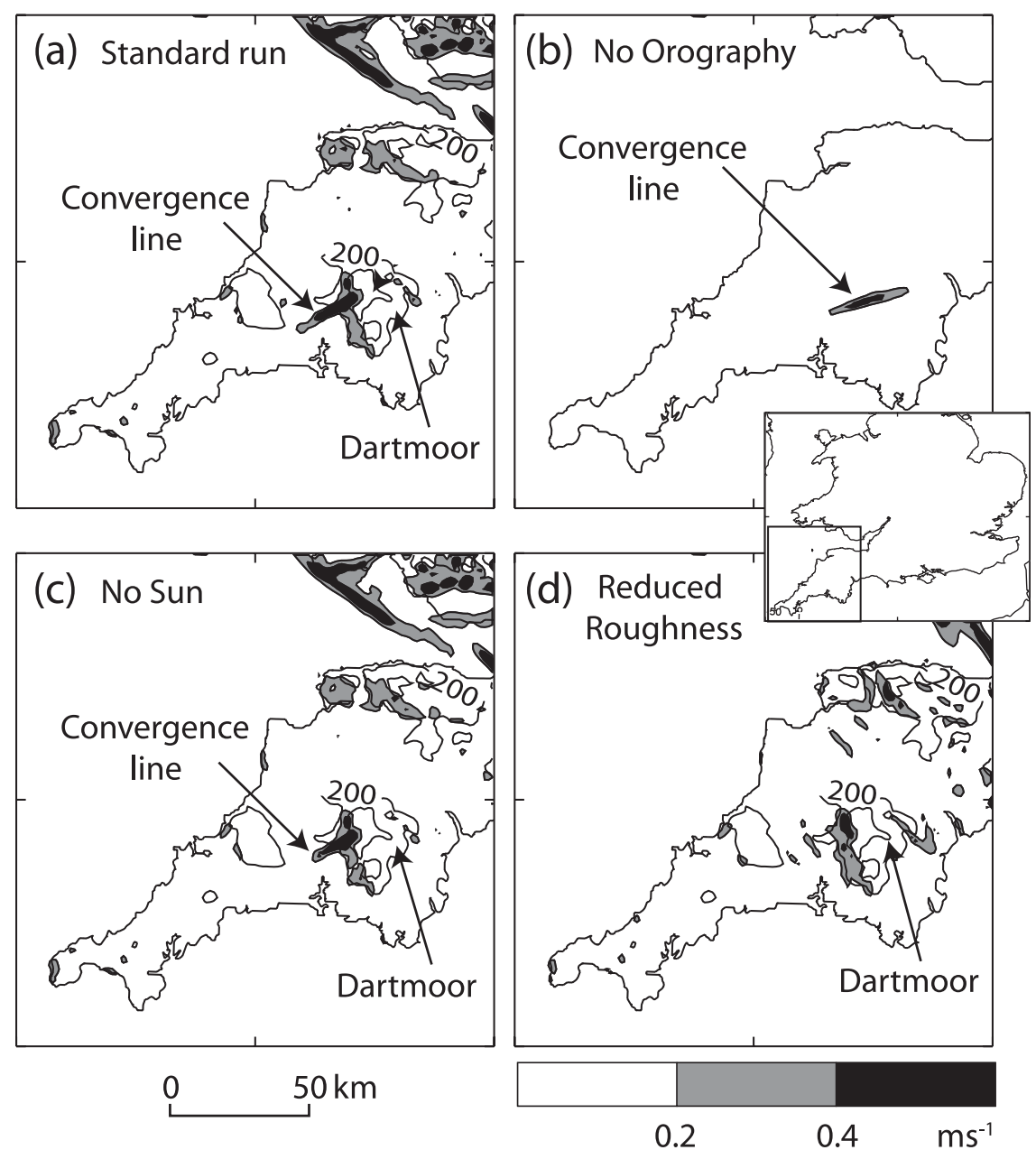

FIG. 5. 925-hPa vertical velocity for the standard, no orography, no sun, and reducedroughness model runs at 0700 UTC. Contours show orography (200 and $400 \mathrm{~m}$ ). The inset locates this figure relative to the rest of the United Kingdom.

with reduced roughness and no solar radiation. The additional removal of the solar heating removes the weak convergence line which implies that it was driven by surface heating.

Figure 7 shows the same three reruns at 0900 UTC. By now the main convergence line is a major feature in the standard run that has moved still farther downstream. The reduced-roughness run has a similar feature although a little weaker and differently positioned and oriented. There is no convergence line in the reduced-roughness and no-sun runs. Therefore by 0900 UTC there is a significant thermal contribution to the convergence line. It is not clear if this is driven by buoyancy gradient, changes in surface stress due to surface stability changes, or enhanced latent heating in cloud. Figure 7 also shows that the convergence line in the standard run deviates to the left (i.e., cyclonically) compared to the reducedroughness run. This shows that the detailed location of the line, and hence of the final shower, is dependent on the details of the surface properties in the model.

In conclusion it appears from these experiments that when the convergence line of interest first appears at around 0700 UTC it is generated by roughness effects. In the next few hours, however, as the sun becomes stronger, thermal effects become more important to the extent so that by 0900 UTC thermal effects alone would have generated a similar convergence line.

We now return to the hypothesis that the convergence line at 0700-0800 UTC is important in the development and location of the deep shower. The reduced-roughness run at 0700 UTC (Fig. 5d) shows no convergence line and at 0800 UTC (Fig. $6 \mathrm{~b}$ there is no convergence line over Dartmoor (the weak one commented on above is forming upstream). Hence, we test the effect of the convergence line on the initiation by looking at the reduced-roughness run. Figure $8 \mathrm{c}$ shows the precipitation 


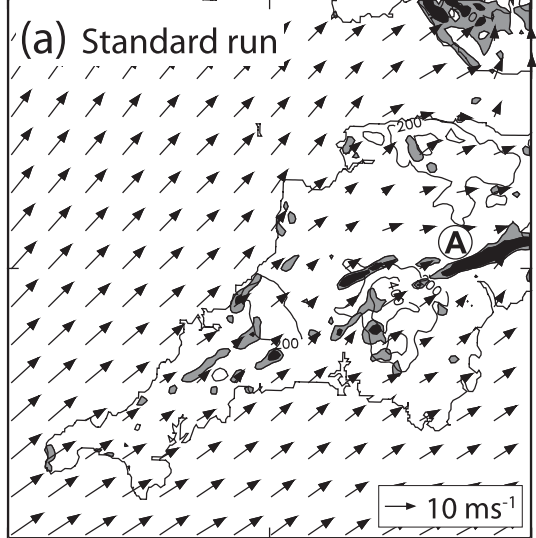

$\quad 50 \mathrm{~km}$

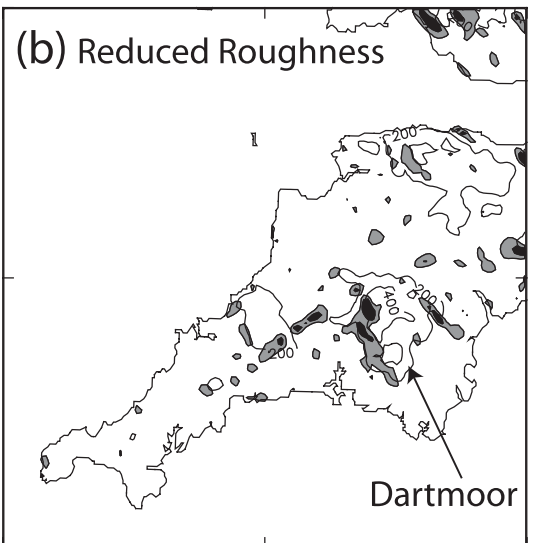

(c) Reduced Roughness No Sun

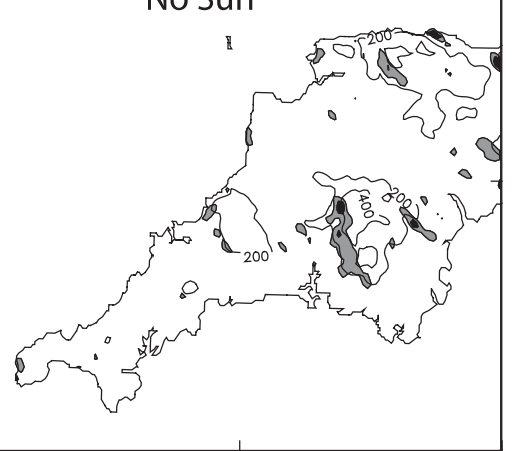

0.2
0.4

$\mathrm{ms}^{-1}$

FIG. 6. 925-hPa vertical velocity at 0800 UTC for standard, reduced-roughness, and reduced-roughness-with-no-sun runs. The vectors in (a) show the 10-m wind field (the number of arrows shown is greatly thinned from the number of model grid points for clarity). The convergence line is labeled $\mathrm{A}$ in (a).

field at 1200 UTC from the model run with reduced roughness. Comparison to Fig. 8a (standard run) shows that the main storm does not exist and instead several small, light showers are present along the convergence line. Figures 8b,d shows along-convergence line cross sections of static stability and cloud water. The static stability field clearly shows the lid, which the shower breaks through in order to deepen at 1100 UTC. In Fig. $8 \mathrm{~b}$ (standard run) the shower can be seen breaking through the lid, whereas the run with reduced roughness
(Fig. 8d) has weaker showers that have not broken through the lid. These results from the reduced-roughness run confirm that the convergence line at 0700-0800 UTC is important for the formation of the storm.

Figure 9 shows the development of the early stages of the showers. In the standard run some clouds have appeared along the convergence line at 0800 UTC, which are absent in the reduced-roughness run. These are the initial clouds that lead to the major shower. By 0900 UTC the clouds in the standard run have further developed

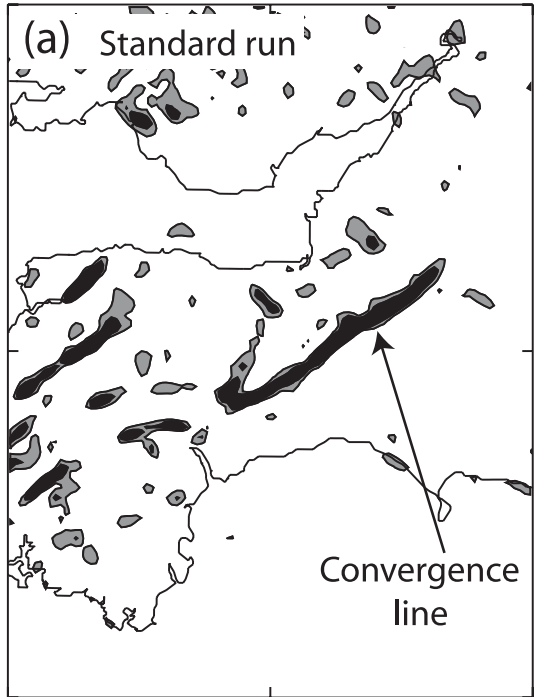

$0 \quad 50 \mathrm{~km}$
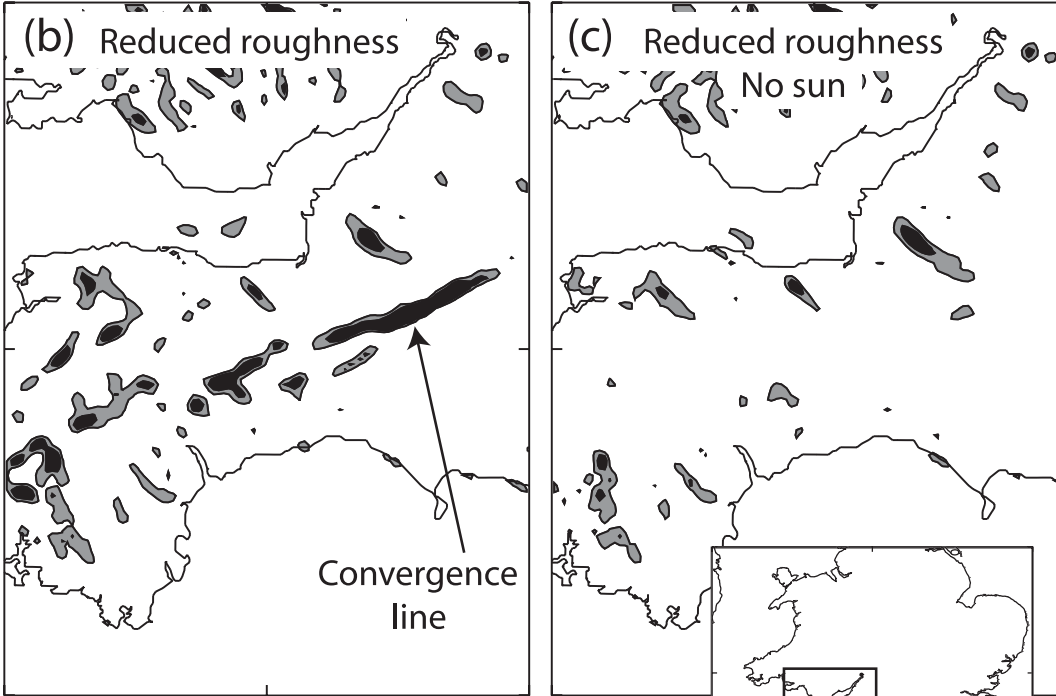

\section{2}

0.4

$\mathrm{ms}^{-1}$

FIG. 7. 925-hPa vertical velocity at 0900 UTC for standard, reduced-roughness, and reduced-roughness-with-no-sun runs. 

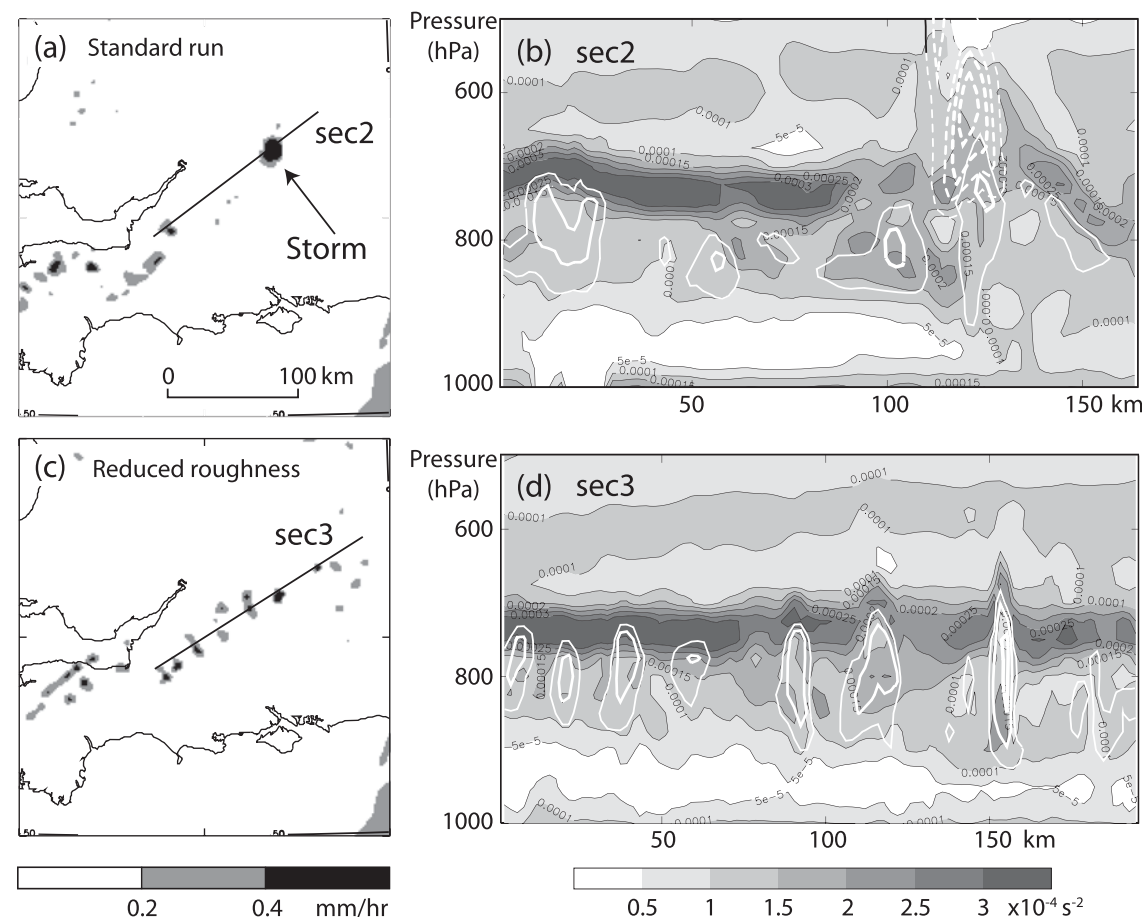

FIG. 8. Comparison of convection at 1200 UTC in standard and reduced-roughness runs: (a),(c) the rain rates; (b),(d) cross sections along the lines in (a) and (c), respectively, with static stability, $\left(\mathrm{N}^{2} \mathrm{~s}^{-2}\right)$ (gray shades), cloud water (solid white contours), and cloud ice (dotted white contours).

(and have nearly reached the stage of precipitating). In the run with reduced roughness, clouds are starting to appear by 0900 UTC, but these lead to the shallow showers seen in Figs. 8c,d. It has been shown above that the convergence line is necessary for the formation and deepening of the one storm of interest. In the next section we will show that the convergence line is not sufficient and that orography also plays a role.

\section{Orographic effects on initiation and development}

Having established that the convergence line and high$\theta_{w}$ tongue are important for the initiation and development of the storm the next questions are why only one deep shower forms on the line and why deep showers do not form on the other convergence lines visible in Fig. 6a.

We hypothesize that the initiation was the result of the collocation of the high $\theta_{w}$ tongue, convergence line, and Dartmoor. The $1.5-\mathrm{km}$ model was rerun with most of the orography unchanged but with Dartmoor removed (Fig. 10). The impact on the final shower at 1200 UTC, shown in Fig. 11c, is similar to that from reducing the roughness - the large storm is removed and replaced by a number of very light showers along the convergence line. Figure 11 shows that although there are still showers present they did not break through the lid of high static stability air. This confirms that Dartmoor is important in the initiation and subsequent deepening.

We now examine the role of Dartmoor in the CI in more detail. Three mechanisms involving orography are often cited as potentially leading to the triggering of convection:

1) Direct lifting leading to condensation and hence the triggering of conditional instability.

2) Reduction in static stability due to lifting of a layer.

3) Enhanced surface heat fluxes over orography. These arise because, as air is lifted over orography, it cools adiabatically, while the surface temperature changes little as it is controlled by shortwave radiation and cooling by longwave radiation; the net effect is enhanced instability in the surface layer. The first and third of these was studied by Crook and Tucker (2005) for shallow orography typical of England.

In Fig. 2 it appears that the convection initiates about $30 \mathrm{~km}$ downstream of Dartmoor in the model. This implies that the initiation is not caused by direct lifting or elevated heating. Barker Schaaf et al. (1988) found that thunderstorms often initiate in particular locations for a given wind direction downstream of mountains in 

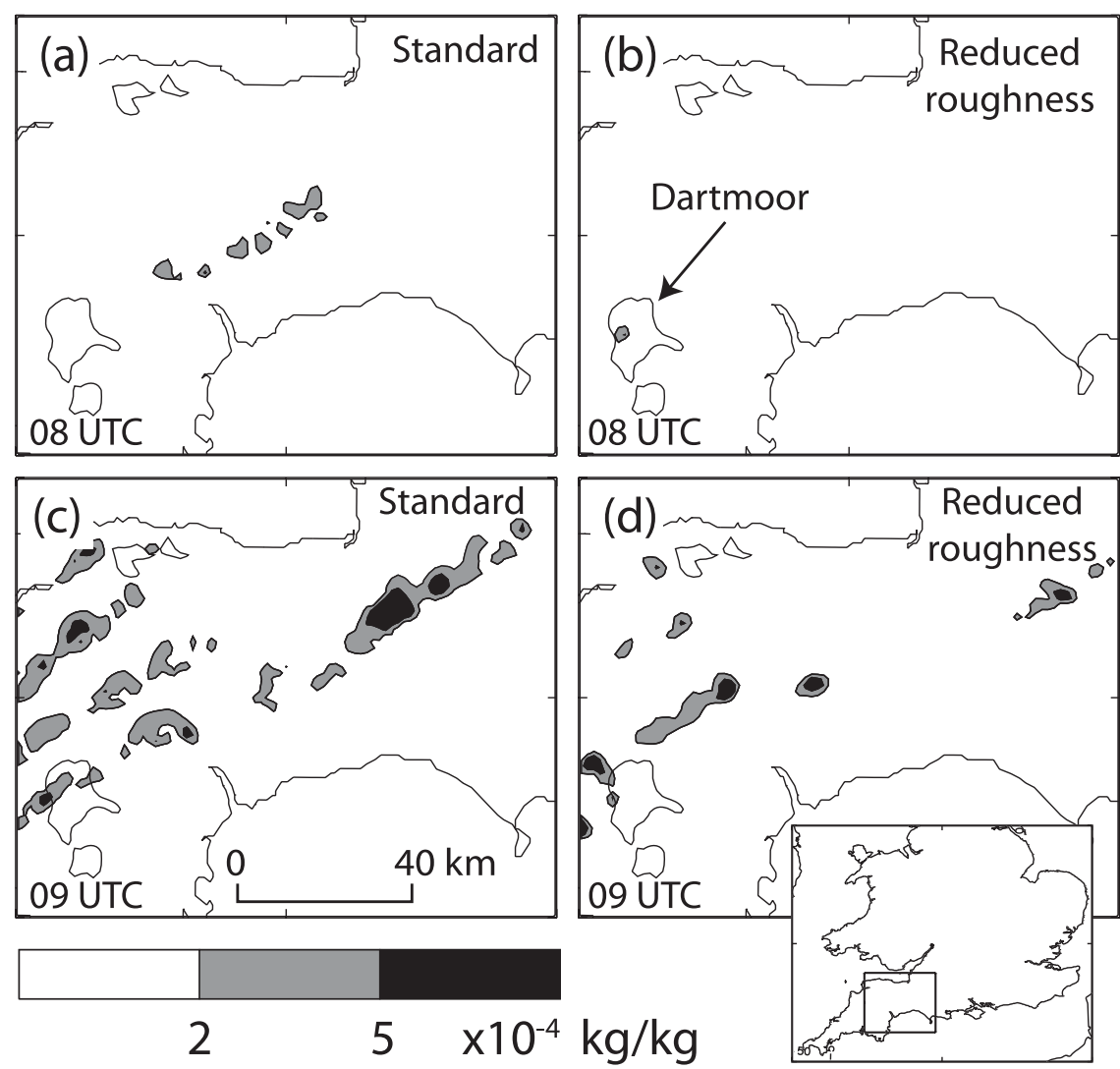

FIG. 9. Cloud liquid water at $800 \mathrm{hPa}$ at 0800 and 0900 UTC comparing the standard and reduced-roughness runs. The 400-m orography contour is shown in black. The inset serves to locate the area in the United Kingdom.

the Rockies. A possible explanation for the initiation downstream of the hill in this case would be the presence of a lee rotor causing ascent some way downstream. However, no reversed flow is seen in the lee of the mountain in the velocity field. Heat fluxes from the standard- and no-Dartmoor runs are plotted in Fig. 12. Figure 12a shows that, while there is a peak in the sensible heat flux near the peak of Dartmoor, there is a stronger peak downstream. The same plot for the run without Dartmoor (Fig. 12b) shows that both these features are related to the presence of Dartmoor-this is emphasized by the difference plot (Fig. 12c). Figures $12 \mathrm{~d}-\mathrm{f}$ show the corresponding fields for the latent heat flux. The overall pattern for latent heat flux is different, with high values behind the front. However, the difference plot (Fig. 12f) shows the same two peaks, on the slopes of Dartmoor and downstream. The downstream peak approximately corresponds to the location where the shower initiates in Fig. 2b so we hypothesize that it is instrumental in the initiation.

The first question is why the peak difference in surface heat flux is located where it is. Figures 13a-c show from
Meteorological Satellite (Meteosat) Second Generation high-resolution visible satellite imagery a reduction of cloud between 0700 and 0800 UTC downstream of Dartmoor. Figures 14a,c show a similar hole in the cloud in the model. The standard run shows a hole downstream of Dartmoor at 0700 UTC, which becomes much more extensive by 0800 UTC. The equivalent fields from the no-Dartmoor run confirm that Dartmoor makes the hole much more extensive. The hole in the cloud at 0700 UTC corresponds to the location of the maximum of the peak in the heat flux in Fig. 12a. The 0700-0800 UTC timeframe also corresponds to the time when the low-level high $-\theta_{w}$ tongue is crossing the same area (Fig. 2c). The convergence line is located along the northern boundary of the main cloud hole in Fig. 14c (standard run at 0800 UTC). The warmed low level air in the hole flows northward into the convergence line in order to play a role in the initiation.

The difference in the $\theta$ between the standard run and one with no solar heating at 0700 UTC along a cross section taken along a line across Dartmoor and through the cloud hole (Fig. 15b) shows significant warming near 


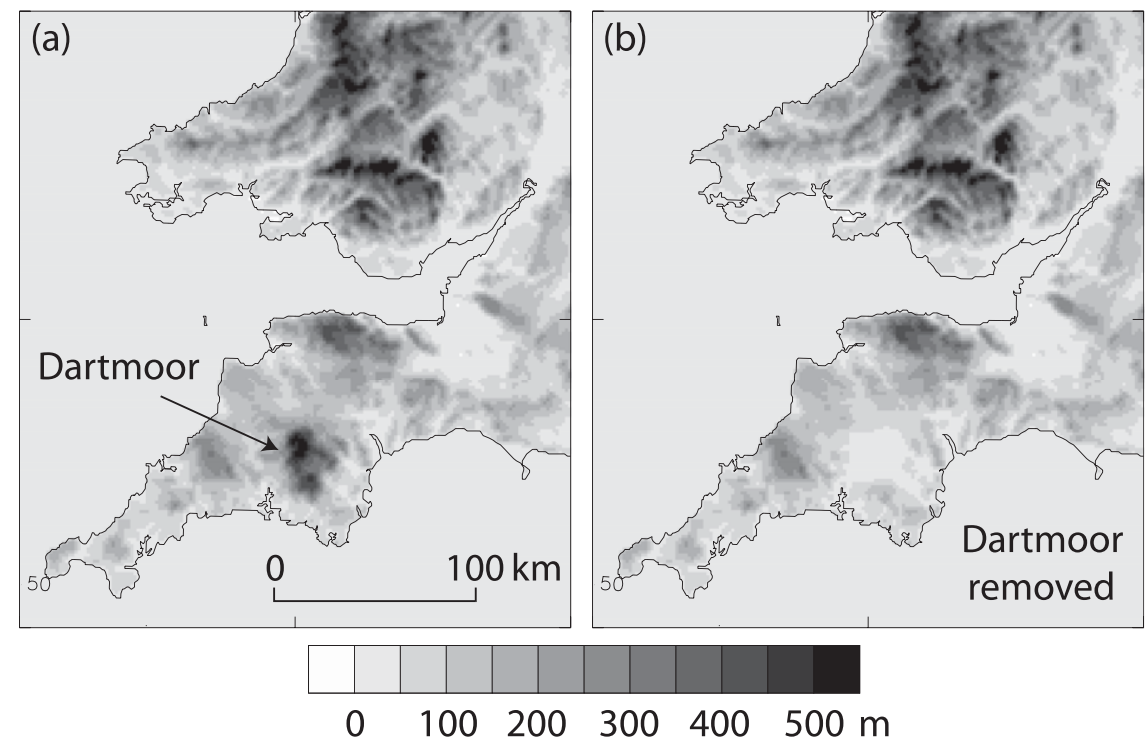

FIG. 10. Model orography over the southwestern part of the domain in standard run and in run without Dartmoor.

the ground in the standard run along most of the section. However, there is much greater heating, with a temperature difference of up to $1.4^{\circ} \mathrm{C}$, downstream of Dartmoor corresponding to the peak in the heat flux and the cloud hole (Fig. 15d). The lower parts of the tephigrams from the two model runs (Fig. 15c) shows that the strongest heating is constrained below a lowlevel stable layer at about $960 \mathrm{hPa}$ (about $300 \mathrm{~m}$ ). This constraint of the surface heating below the low-level stable layer is important because it enables the change in $\theta$ to be sufficient to initiate convection. Heating through the cloud hole produces a much larger effect than the elevated heating because the presence of cloud around the peak of Dartmoor does much more to reduce surface fluxes than the difference in height of a few $100 \mathrm{~m}$ does to increase them. The combination of the low-level tongue of high- $\theta_{w}$ air with the additional surface heat and moisture flux raises $\theta_{w}$ enough to allow the shower to deepen later by breaking through the lid.

These findings are illustrated by considering cross sections across the convergence line at various stages in development. Figures 16a,b show cross sections at 0700 and 0800 UTC, respectively, of the difference between $\theta_{w}$ in the standard run and in the run without Dartmoor along cross sections shown in Figs. 16c,d as well as an indication of the location of the lid by a contour of high static stability. This shows an enhancement in $\theta_{w}$ across a region about $15-20 \mathrm{~km}$ across and extending relatively uniformly up to the lid, with peak enhancement centered on the convergence line.

Figures $16 \mathrm{c}, \mathrm{d}$ show the difference in a conditional instability parameter between the two runs. This pa- rameter is the difference between low-level $(950 \mathrm{hPa})$ $\theta_{w}$ and $\theta_{s}$ above the lid $(700 \mathrm{hPa})$. Here $\theta_{s}$ is the $\theta_{w}$ air would have if saturated. If a low-level parcel lifts moist adiabatically (with no mixing and so conserving $\theta_{w}$ ) it will remain buoyant if the environment has $\theta_{s}$ lower than the parcel. Only positive differences between runs are shown; numerous small negative areas exist farther downstream presumably due to wave activity. These figures show higher instability in the standard run in a number of lines, of magnitude consistent with the lowlevel $\theta_{w}$ differences shown in Figs. 16a,b. However, the $14^{\circ} \mathrm{C} 950-\mathrm{hPa} \theta_{w}$ contour shows that only the leading part of the convergence line discussed above lies in the high- $\theta_{w}$ tongue.

Figure 17 shows comparisons (with and without Dartmoor) of cross sections at 0800 (Figs. 17a,b), 1000 (Figs. 17c,d), and 1200 UTC (Figs. 17e,f) through the low-level air that forms the shower. Gray shades show $\theta_{s}$ above the lifting condensation level (LCL; dashed white line) and $\theta_{w}$ below. Figure 17a shows a lower- $\theta_{s}$ layer beneath a relatively homogeneous higher- $\theta_{s}$ layer above about $2200 \mathrm{~m}$. The interface is the high static-stability lid shown in Fig. 16b. At this stage the lower-level $\theta_{w}$ and $\theta_{s}$ above the lid are very similar. The convergence line is marked by upward motion below the lid about $45 \mathrm{~km}$ along the cross section, with a gravity wave-like response above. Cloud fills this layer above the LCL at and to the north of the convergence line, with some thin cloud to the south. A negative vertical $\theta_{s}$ (and hence $\theta_{w}$ ) gradient exists in the cloud, with highest $\theta_{s}$ at the convergence line. Furthermore, this cloud-base $\theta_{s}$ closely matches the $\theta_{w}$ below cloud at the convergence line, 

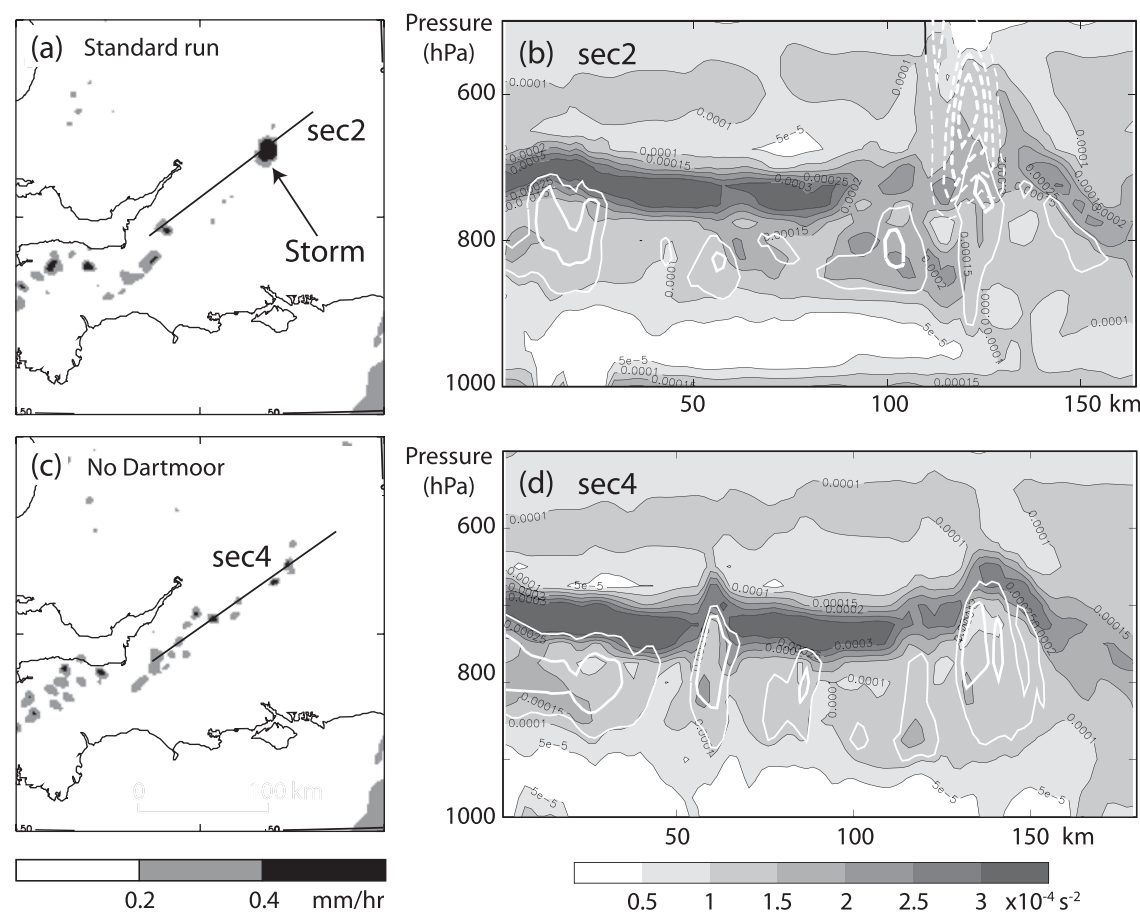

FIG. 11. Comparison of convection at 1200 UTC in standard and no-Dartmoor runs: (a),(c) the rain rates; (b),(d) cross sections along the lines in (a) and (c), respectively, with static stability $\left(\mathrm{N}^{2} \mathrm{~s}^{-2}\right.$ ) (gray shades), cloud water (solid white contours), and cloud ice (dotted white contours).

while away from the line the below cloud air has generally lower $\theta_{w}$. The $\theta$ contours show that the belowcloud region is only weakly stratified or well mixed, suggesting efficient vertical turbulent transport. Thus, in the region of the convergence line below-cloud air is being lifted, both by resolved updrafts and turbulence, into the cloud base where it is moist unstable up to the lid. If parcels were transported to the lid from the cloud base without mixing, they would be buoyant as their $\theta_{w}$ is slightly higher than $\theta_{s}$ above the lid (by almost $1 \mathrm{~K}$ ) but turbulent mixing with the lower $\theta_{s}$ air above presumably renders this air stable. The $\theta$ contours show evidence of enhanced latent heating in clouds at the convergence line but lifting at the cloud top.

Figure 17b shows the same cross section in the run without Dartmoor. At this time the differences are small but significant; the lower $\theta_{w}$ below the lid has been highlighted in discussing Fig. 16. In addition, ascent in the clouds is weaker, but still present and the cloud to the south of the convergence line is continuous (if thin) with lower $\theta_{s}$, serving to enhance the lid in this region.

Similar features and differences are shown by Figs. $17 \mathrm{c}, \mathrm{d}$ at 1000 UTC, but by this time the general features are stronger; the low-level high $\theta_{w}$ and $\theta_{s}$ air extends higher into the cloud layer and the lifting of the lid is more evident. Figure $17 \mathrm{~d}$ shows lower $\theta_{w}$ and $\theta_{s}$ in the low-level air by up to $0.5 \mathrm{~K}$ compared to Fig. $17 \mathrm{c}$ with less cloud water, weaker ascent, and less lifting of the lid by $200-300 \mathrm{~m}$ in the convergence line.

Figures 17e,f are taken through the single deep shower in the standard run at 1200 UTC. Figure $17 \mathrm{e}$ shows the shower cloud as a tongue of high $\theta_{w}$ and $\theta_{s}$ air, with $\theta_{w}$ and $\theta_{s}$ at the cloud top matching that at the surface and exceeding that in the environment above the lid. The run without Dartmoor still shows enhancement of low-level $\theta_{w}$ and $\theta_{s}$ at the convergence line but to a value not exceeding that above the lid. These comparisons demonstrate that it is the enhancement of low-level $\theta_{w}$ by enhanced surface fluxes of heat and moisture to a value that exceeds that at the lid sufficiently (including effects of mixing in clouds) to produce moist instability at the lid that triggers the deep shower.

To test the surface warming hypothesis a further rerun of the $1.5-\mathrm{km}$ model has been carried out in which the surface albedo is set to 1.0 in a $25-\mathrm{km}$ radius circular area downstream of Dartmoor (Fig. 18). This mimics the effect of clouds on incoming shortwave radiation by preventing radiative heating of the ground without drastically changing the dynamics of the flow and conserving energy. The impact is slightly more severe than the actual impact of cloud, as there is some residual shortwave radiation beneath the cloud in the "no 

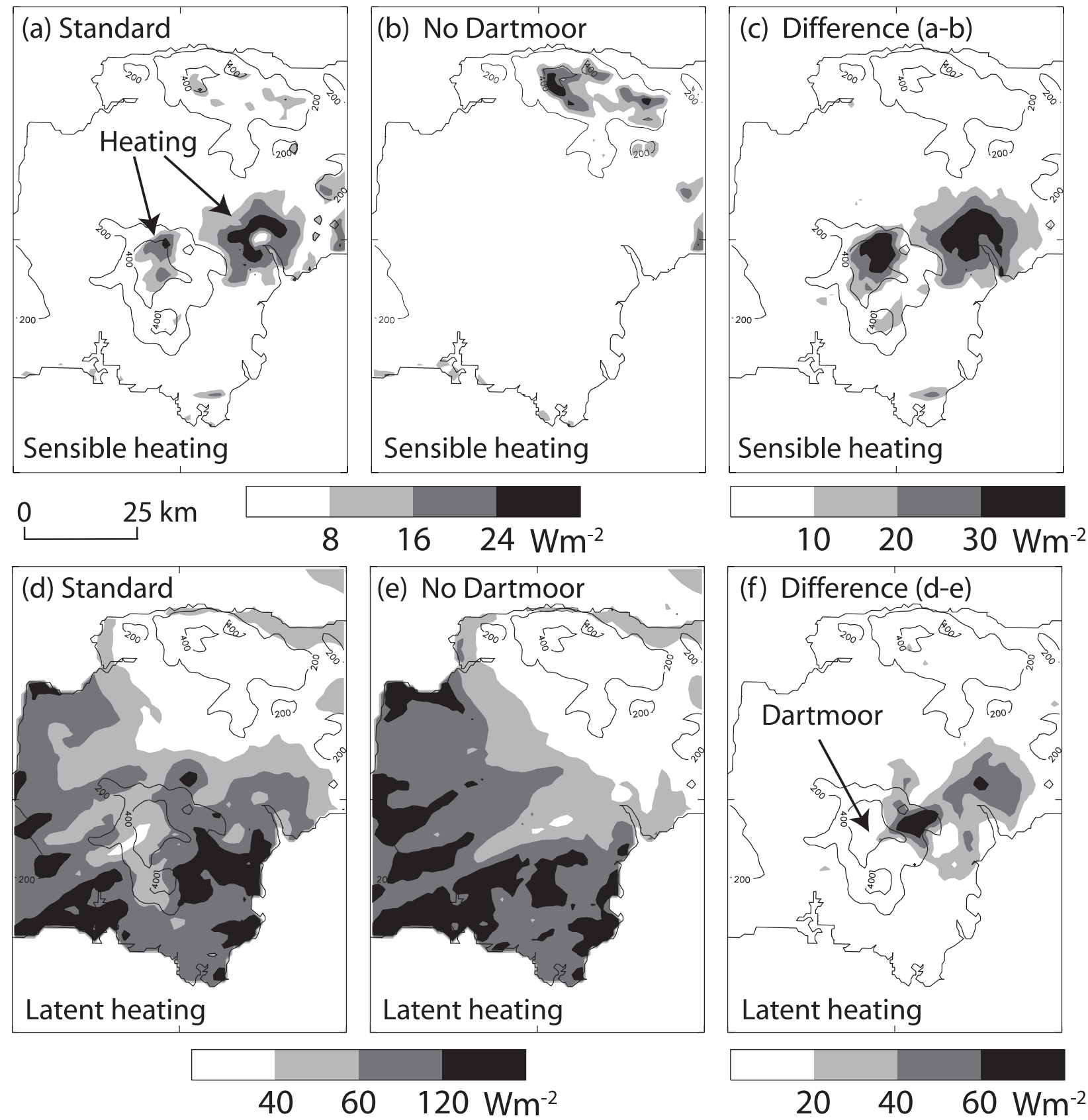

FIG. 12. Comparison of surface heat fluxes in standard no-Dartmoor runs at 0700 UTC. (Note the different scales in the different frames.) (a),(b) Sensible heating; (c) the difference in sensible heating; (d),(e) latent heating; and (f) the difference in latent heating.

Dartmoor" case, but this amounts to only a few watts per meters squared.

Figure 18 compares the development of the shower cloud in the standard and modified-albedo runs. At 0700 UTC the two runs are very similar since the shower cloud has not yet formed. By 0800 UTC the cloud is already much weaker with the modified albedo. By 0900 UTC the shower of interest, although discernable, is very greatly weakened. This weakening is sufficient to stop the shower breaking through the lid at around 1100 UTC. Figures 19c,d show the effect of this modified albedo on the final shower at 1200 UTC compared with the standard run (Figs. 19a,b). The heavy shower is replaced by a few very light ones in a similar way to the runs without roughness and without Dartmoor. This shows that the heating of the surface downstream of 

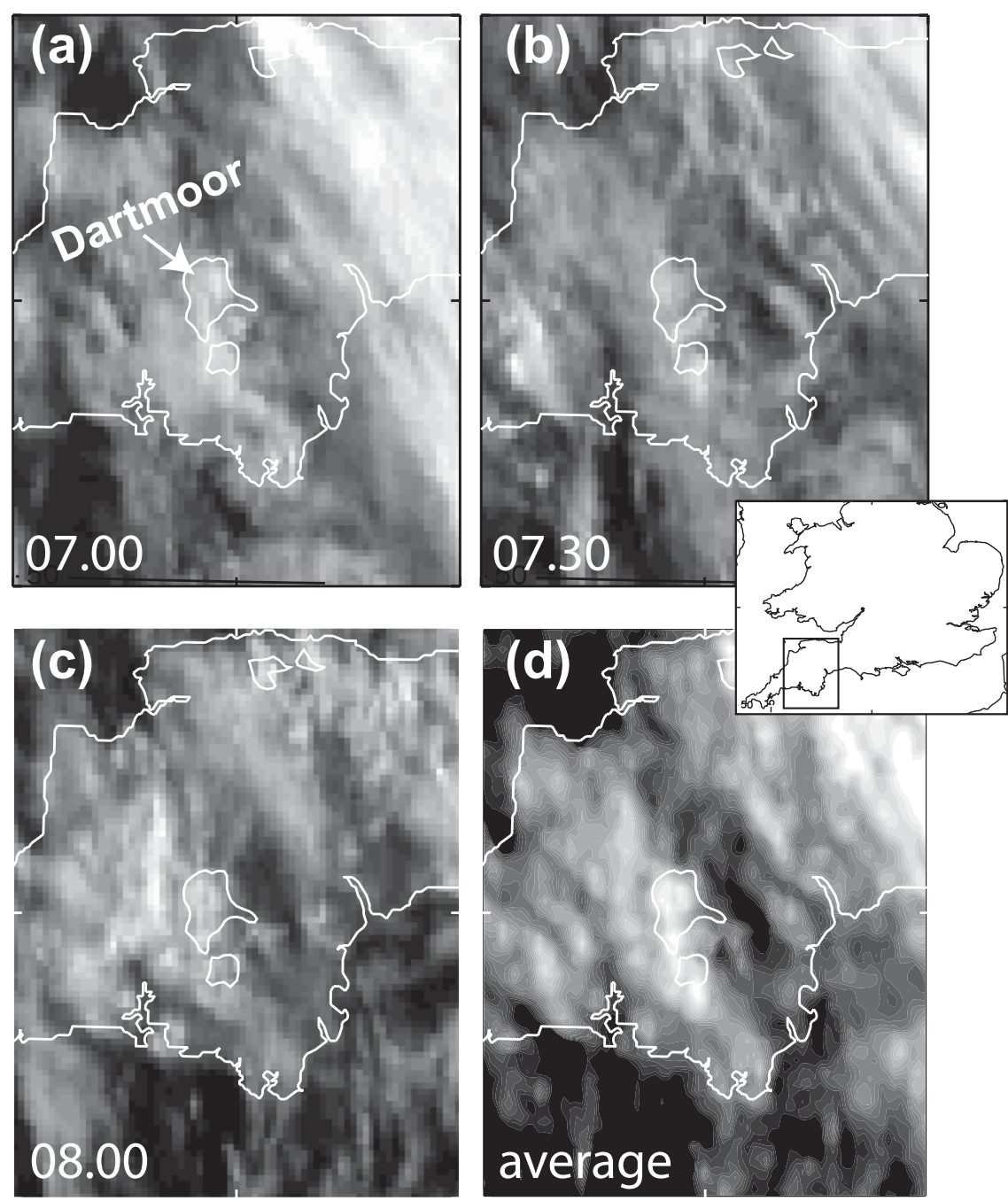

FIG. 13. Meteosat Second Generation high-resolution visible imagery showing hole in cloud downstream of Dartmoor at 3 times and the 3 fields are averaged. The 400-m contour serves to locate the highest parts of Dartmoor.

Dartmoor is essential for the formation of the major shower. Cross sections from the modified-albedo run similar to those in Fig. 17 (not shown) are extremely similar to the no-Dartmoor run downstream of Dartmoor.

Having established that solar heating through the hole in the cloud is important for CI the next question is why the cloud hole forms downstream of Dartmoor. Three possible explanations can be considered:

1) Loss of cloud water over the orography through precipitation or direct deposition of cloud water to the surface. However, neither happens in the model.

2) Evaporation of cloud through enhanced surface sensible heat flux over orography. Figure 12 shows very weak additional warming over Dartmoor (less than $25 \mathrm{~W} \mathrm{~m}^{-2}$ ). This would be able to evaporate of order $10^{-5} \mathrm{~kg} \mathrm{~s}^{-1}$ cloud water. Given the liquid water path of about $0.3 \mathrm{~kg} \mathrm{~m}^{-2}$, the transit time over this patch of enhanced surface flux would have to be about $9 \mathrm{~h}$ to evaporate the cloud, much less than the actual transit time of less than an hour.

3) Evaporation of cloud through adiabatic descent. If the flow is simply lifted in proportion to the height of the orography, additional condensation would occur over the orography but this would evaporate on the lee side of the hill, returning the liquid water content to that upstream. Asymmetry in the cloud requires asymmetry in the flow, with more descent of air on the lee side than ascent on the windward side. Figure $15 \mathrm{~d}$ shows streamlines of the flow and the cloud field over Dartmoor from the standard run. The streamlines indicate that cloudy air on the upstream side 

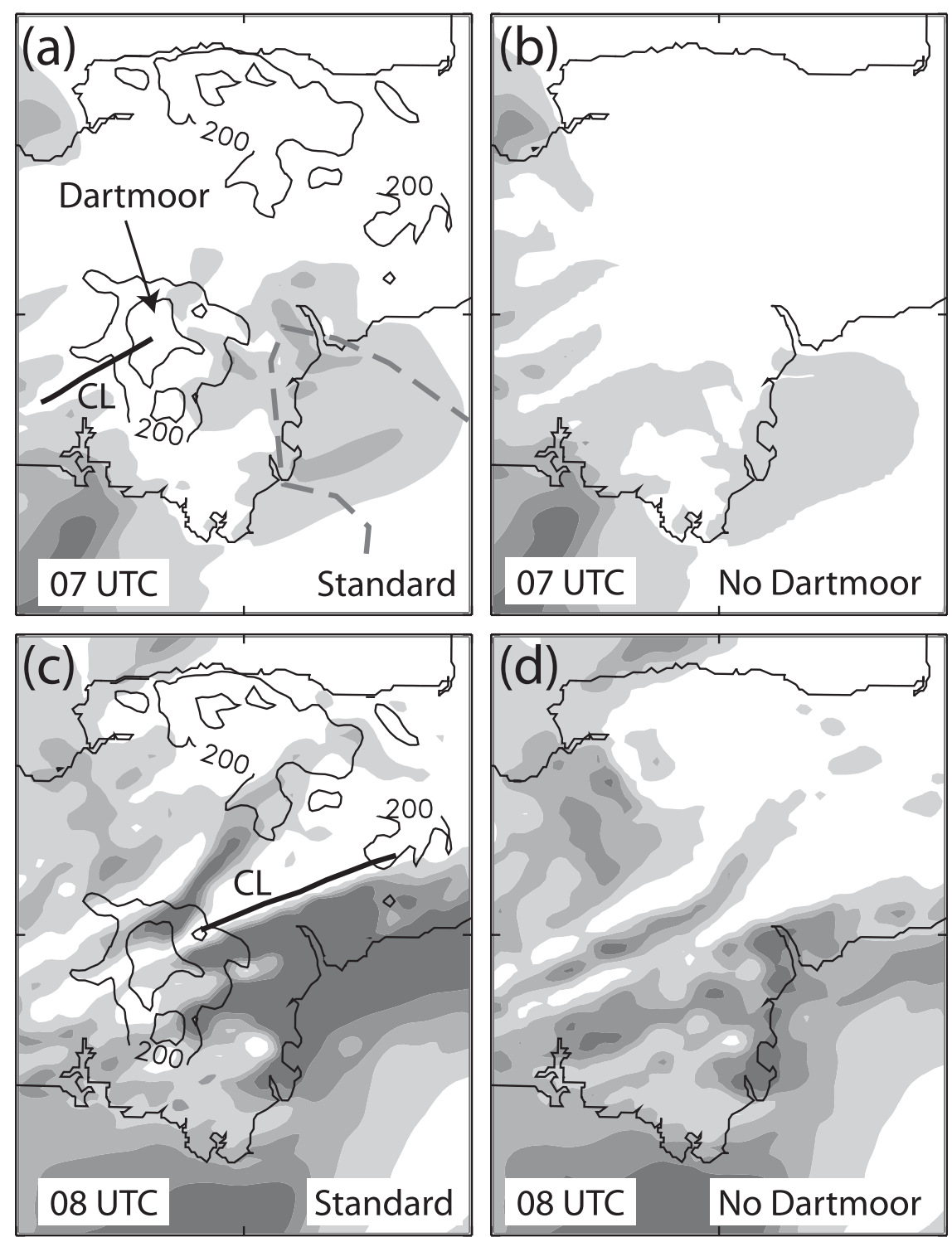

\section{$0.35 \quad 0.55 \quad 0.75 \quad 0.95$}

FIG. 14. Simulated albedo from standard and no-Dartmoor model runs. The convergence line in the standard run is marked "CL."

descends to around or below cloud base on the downstream side, consistent with leeside descent being the primary mechanism for evaporating cloud.

Thus, the cloud hole appears to be due to asymmetric flow over the mountain with more descent on the lee side than ascent on the upwind slope. This asymmetric flow may have been associated with high static stability in the frontal zone. Detailed analysis of the flow regime (including effects of multilayer stability structures; e.g.,
Vosper 2004) is beyond the scope of this paper. A great deal of validation of the MetUM for orographic flow has already been performed (e.g., Smith 2004; Smith et al. 2006; Webster et al. 2008), and we have confidence that the model is capable of reasonably accurate representations of this flow over orography at these scales. The more important issue is that the flow is likely to be sensitive to the accuracy of the larger-scale vertical profiles. While the detailed flow cannot be verified, the fact that the model produces a cloud hole caused by 

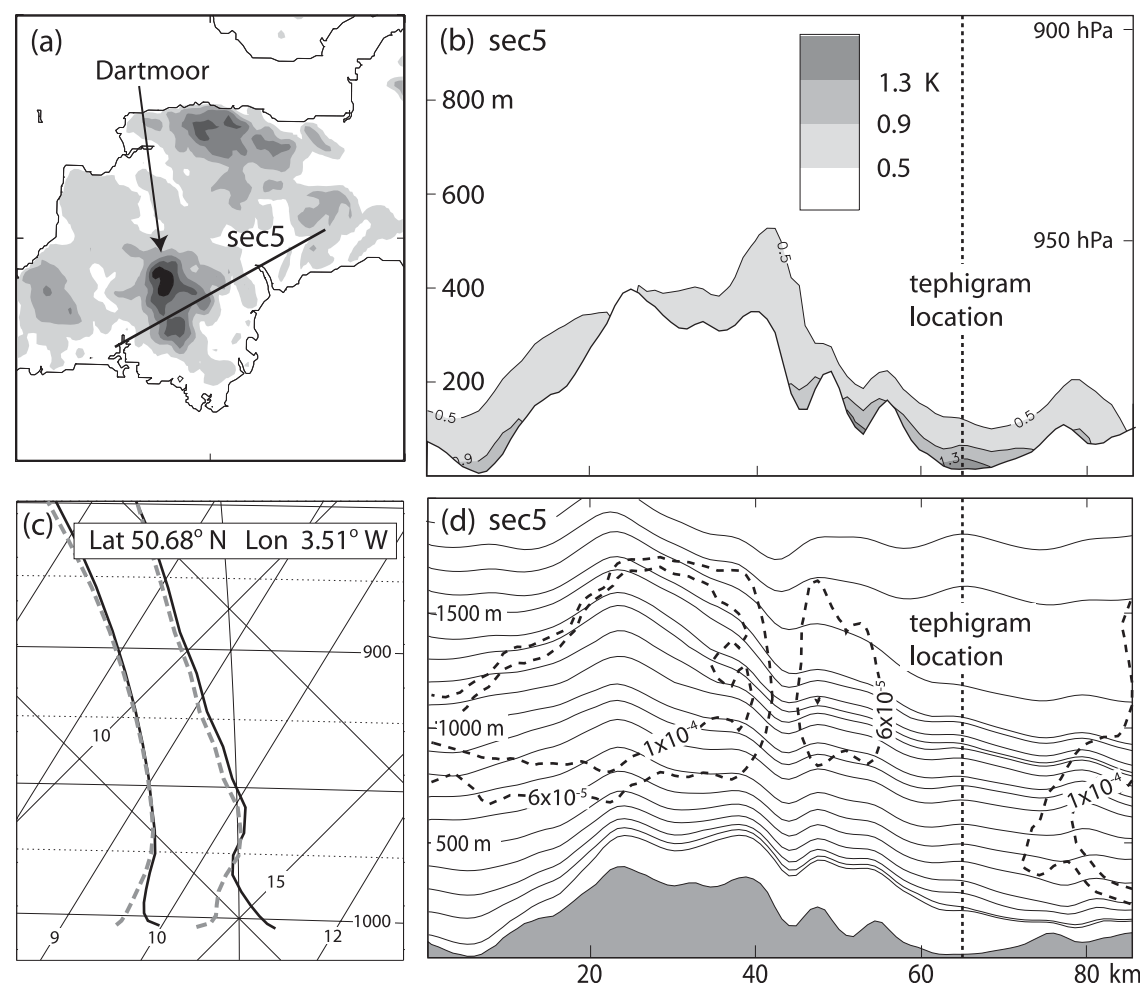

FIG. 15. (a) Location and (b) cross section across Dartmoor in an along-wind direction not in the convergence line of difference in $\theta$ between the standard run and the run with no sun at 0700 UTC. (c) Tephigram at the same time at the point indicated in (b),(d) for standard run (solid lines) and no sun run (dashed lines). (d) The same cross section as (a) with cloud water contoured (dashed lines) and streamlines (solid lines).

downslope flow is consistent with the observed cloud hole also being the result of downslope flow and that both are the result of the passage of the high static stability air at low levels over Dartmoor.

\section{Discussion}

M07 showed the role of the low-level tongue of high $\theta_{w}$ air and convergence line in CI. We have deduced from experiments changing orography, surface roughness, and solar heating that orography was not important but both surface roughness and solar heating played a role in forming the convergence line. Surface roughness was the key factor at earlier times. Later in the morning, when solar heating had some impact, it is likely that some of its impact was to increase the surface drag over land by increasing the vertical mixing of momentum, rather than just through horizontal buoyancy gradient effects. These experiments also show, unequivocally, that the convergence line was essential, though not sufficient, for the initiation of the shower.
The reason for only a single storm is more complex. The initial precursor cloud in the convergence line formed at around 0700 UTC close to Dartmoor, which extends up to above $500 \mathrm{~m}$ and so produced a substantial perturbation to the boundary layer flow. Experiments have demonstrated that Dartmoor was necessary for the formation of the deep storm, but the mechanism was neither elevated surface heating nor lifting by the orography. A combination of the early time of day and the formation of a layer of cloud over land meant the perturbation in surface heating was too small to have enough impact (though, had the passage of the system occurred later in the day, the elevated heating alone may have been sufficient to trigger the shower). The flow induced by Dartmoor did not trigger initiation through lifting but instead produced a large perturbation in surface heating about $30 \mathrm{~km}$ downstream. This was associated with the evaporation of the layer cloud by descent in the lee of Dartmoor. The resulting heating through the downstream cloud hole was much more important than the elevated heating effect, especially since there were clouds in the area of the highest ground. We have studied the detailed mechanism for 

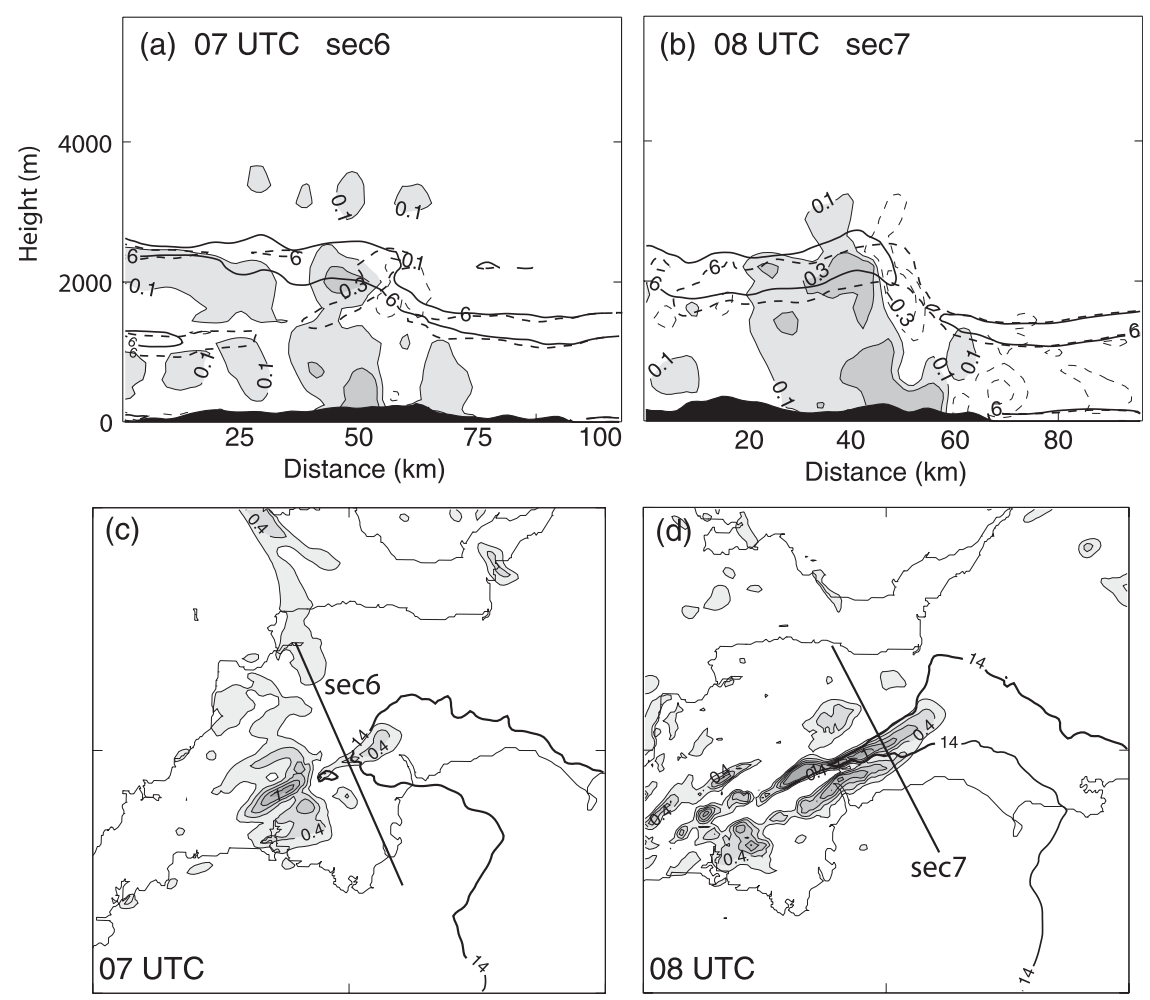

FIG. 16. (a),(b) Vertical cross sections (north-south) along the lines (c),(d) shown by thick straight lines. Gray shades show difference between $\theta_{w}$ in the standard run and in the run without Dartmoor. Negative differences are shown by thin dashed contours. Thick black contours show static stability $=6 \mathrm{~K} \mathrm{~km}^{-1}$, solid for reference, dashed for run without Dartmoor. (c),(d) The difference between $\theta_{w}$ at $950 \mathrm{hPa}$ and $\theta_{s}$ at $700 \mathrm{hPa}$ for the two runs (see text for details). Thick black contours show $\theta_{w}=14 \mathrm{C}$ at $950 \mathrm{hPa}$.

this flow regime but assume that it arose from blocking of low-level flow by Dartmoor, possibly aided by the 700-hPa stable layer.

Experiments artificially enhancing the surface albedo show that the enhanced surface radiation resulting from the cloud-clearance produced sufficient additional surface heat (and moisture) flux into the air feeding into the convergence line to increase the $\theta_{w}$ of the tongue of already high $\theta_{w}$ air. This was enough to ensure that the cloud that formed in the line was sufficiently buoyant to overcome the remaining convective inhibition in the lifted lid. This heating was constrained near the surface by a layer of higher stability at around $960 \mathrm{hPa}$ associated with the warm sector (high $\theta_{w}$ tongue).

This case illustrates the role of a "storm-resolving" model for forecasting convective storms. The model resolves very well both the mesoscale structure of the frontal system leading to the widespread area of potential instability and the inhibiting lid, and the mesoscale features of the low-level flow (coastal and orographic effects) leading to the initiation of the storm. The model needs to have sufficient resolution to produce realistic storm triggering and development but the detailed storm structure, in this type of case, is less critical. In other types of cases, for example when secondary initiation is important, the structure of the storms might be more important.

Many of the important features of this case, especially the convergence line, are not evident in routine observations, and the special observations conducted during CSIP were essential in providing confidence in the model simulations. The evidence available from clear-air radar (M07) prior to or around the deepening of the shower at around 1100 UTC was particularly valuable. Having thus established confidence in the accuracy of the standard forecast, the storm-scale model has provided a valuable analytical tool for understanding the combination of mechanisms operating. In this case, many aspects of the model, including dynamics of orographic and convective flow, radiation, surface exchange, boundary layer, and cloud parameterizations, have all contributed to the accurate forecast.

Given a sufficiently accurate model (both resolution and formulation) and sufficiently accurate large-scale 

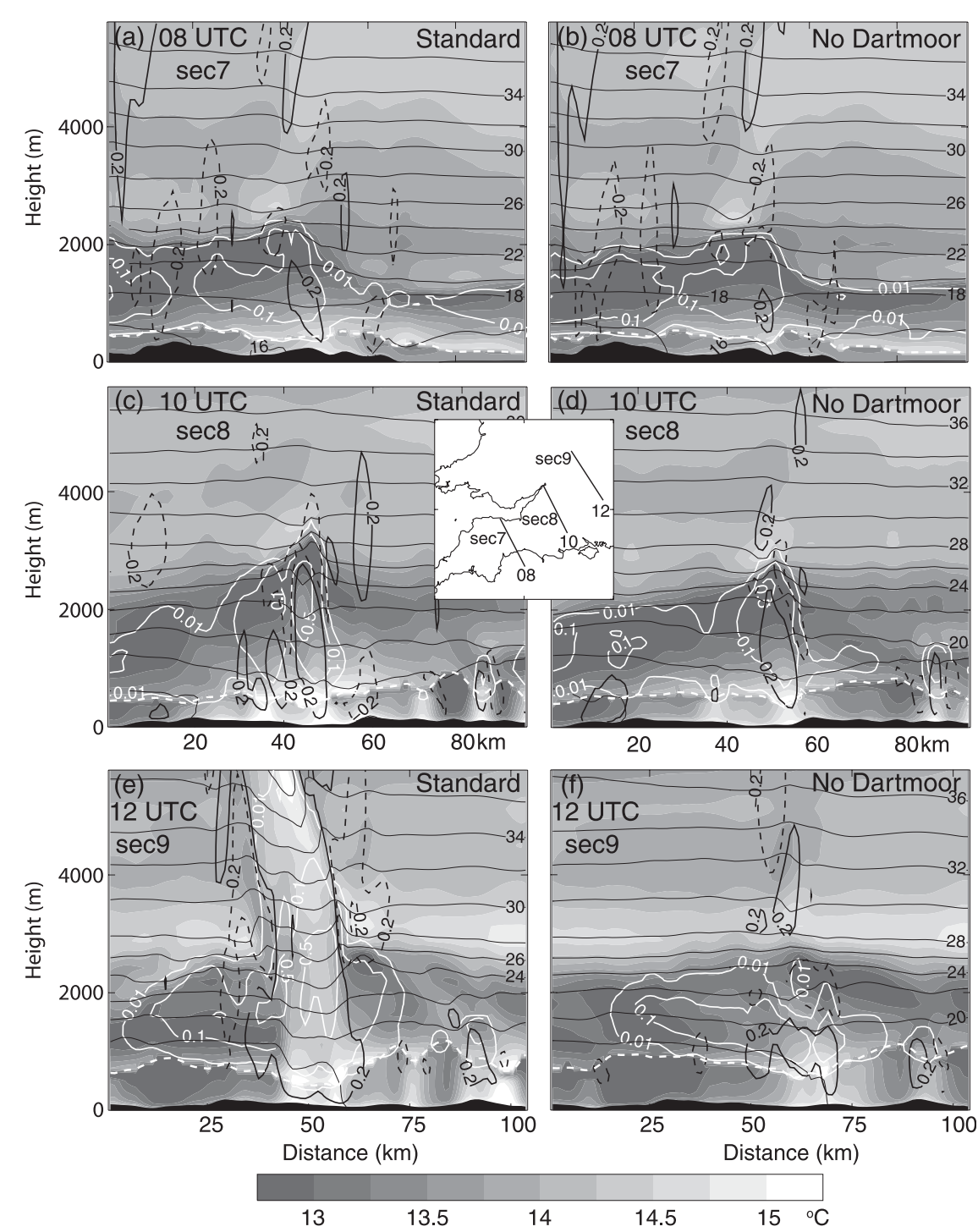

FIG. 17. Cross sections (north-south) at (a),(b) 0800; (c),(d) 1000; and (e),(f) 1200 UTC of $\theta_{s}$ above the LCL and $\theta_{w}$ below (gray shades), $\theta$ (thin black contours), cloud liquid water (white contours), and vertical velocity (thick black contours). The LCL is shown by the dashed white line. (left) Standard run and (right) run without Dartmoor. Cross-section positions are shown in the inset. The solid black area shows the orography.

forcing, it is likely that the timing and location of this storm was highly predictable. This is consistent with the ideas of Done et al. 2008, manuscript submitted to Quart. J. Roy. Meteor. Soc.). They propose that locations of storms that initiate in an environment with relatively high convective inhibition are much more predictable than storms with only weak inhibition over a wide area of potential instability. In this case the important coastal and orographic effects are likely to be quite predictable; the precise nature and position of the convergence line depends on the surface roughness that is reasonably well known (though could un- doubtedly be improved). The orographic downslope flow may be more sensitive to modeled stability, but, in this case, only needs to be sufficiently strong to evaporate the layer cloud. The result did, however, also depend on the frontal representation being correct. This was controlled by the larger-scale, coarserresolution models providing the initial and boundary conditions, and the data assimilation schemes employed therein. It would be interesting to investigate an ensemble of larger-scale forecasts to study the importance of variations of timing and structure of the front. 

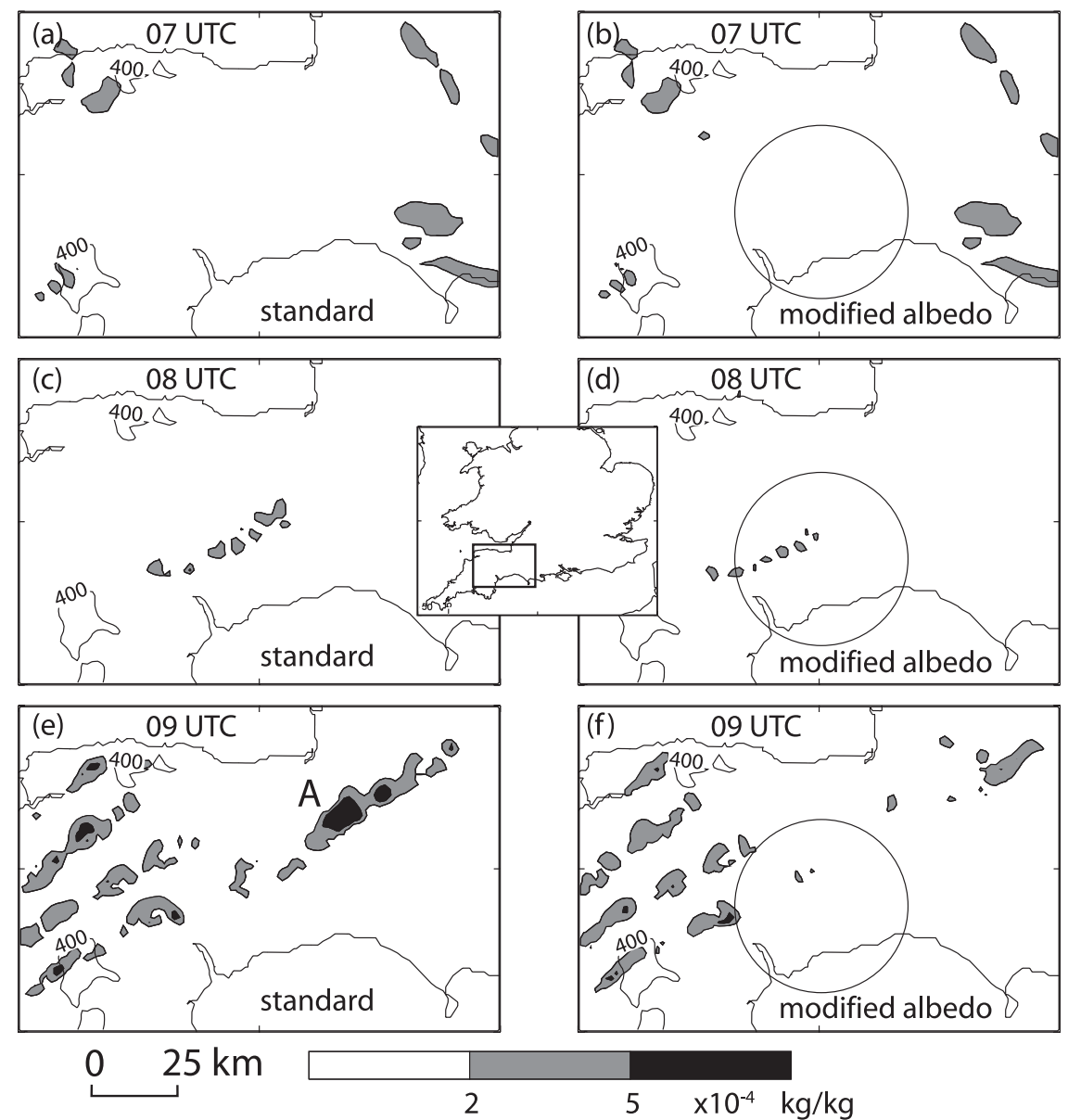

FIG. 18. Cloud liquid water at $800 \mathrm{hPa}$ at 0700,0800 , and $0900 \mathrm{UTC}$ in the standard and modified albedo runs. The circle on the modified albedo frames shows the area in which the albedo was set to 1 . The shower that becomes the main shower is marked " $A$ " in the 0900 UTC standard run frame.

\section{Conclusions}

This paper has examined the mechanisms leading to the initiation of an isolated storm that developed during CSIP IOP1 on 15 June 2005 in southwest England. The observational analysis by M07 showed that the isolated storm developed in a favored location where a local low-level convergence line intersected a low-level tongue of high $\theta_{w}$ air associated with a frontal zone (with a split front structure). This happened behind the upper-level part of the frontal zone where lower $\theta_{w}$ air in the midtroposphere had advected above the higher $\theta_{w}$ air and created potential instability. Although this storm was not particularly severe, convective rainfall events over the United Kingdom that were deemed extreme have also been found to share similar features in their initiation (Golding et al. 2005; Roberts 2008).

M07 were unable to identify either the origin of the convergence line or why only a single storm developed, although they speculated that the convergence line was due to "peninsula convergence," a common feature in this area. This paper has addressed these questions using a series of experiments with modified high-resolution forecasts of the event using the MetUM at $1.5-\mathrm{km}$ grid length. This has been possible because the underlying operational $12-\mathrm{km}$ forecast reproduced the key features described above quite accurately, resulting in a single isolated storm that formed very close to that observed both in space and time.

This case provides an excellent example of the need for a number of factors combining to trigger a single, highly predictable storm and shows that a model can capture them. We have demonstrated that the single storm was caused by a combination of the following:

1) A split frontal structure with low $\theta_{w}$ air overrunning a forward-sloping tongue of high $\theta_{w}$ air. 

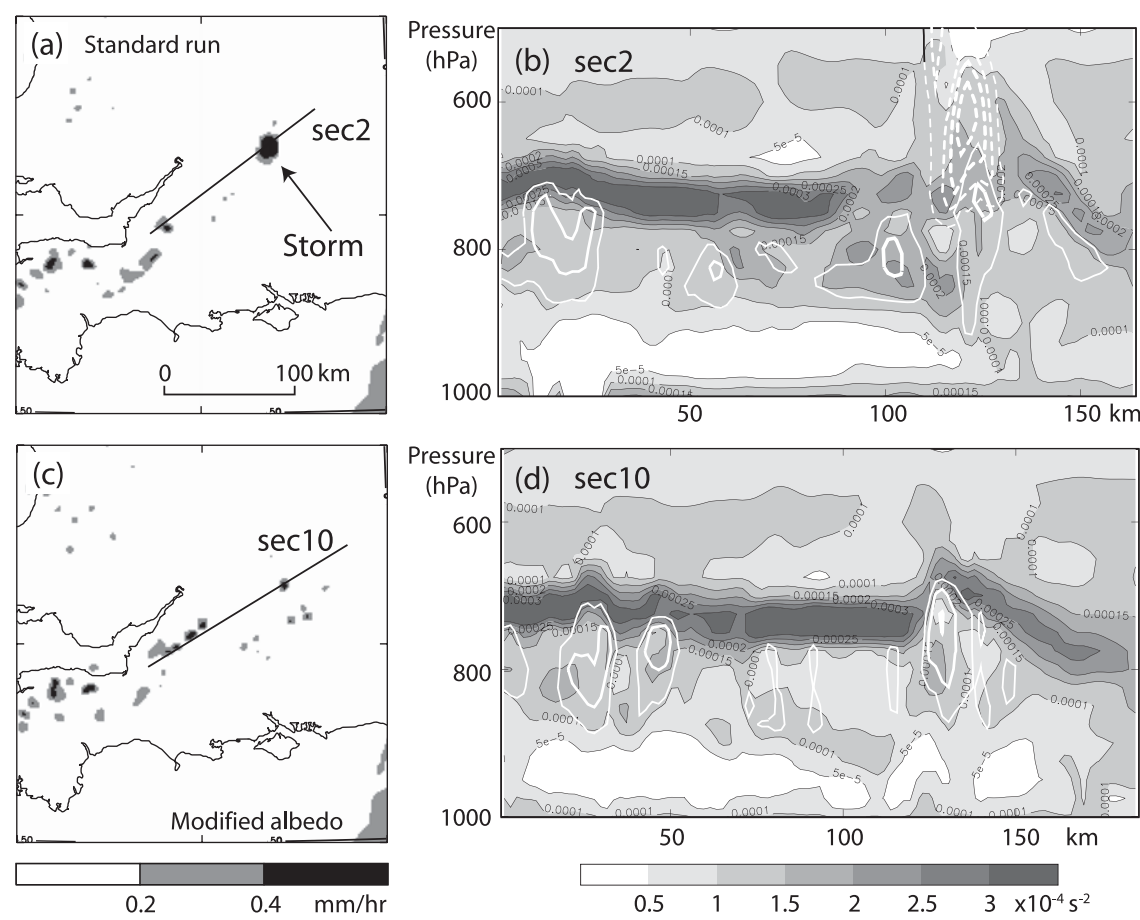

FIG. 19. Comparison of convection at 1200 UTC in standard run and modified albedo run. (a),(c) The rain rates; (b),(d) cross sections along the lines in (a) and (c), respectively, with static stability, $\left(\mathrm{N}^{2} \mathrm{~s}^{-2}\right)$ (gray shades), cloud water (solid white contours), and cloud ice (dotted white contours).

2) A "lid" above and behind the high $\theta_{w}$ tongue causing widespread inhibition of deep convection.

3) A convergence line roughly normal to the front largely driven by land-sea roughness contrast, with the southwest peninsula orientated roughly along the low-level flow.

4) A period of asymmetric flow over Dartmoor with stronger downstream descent possibly associated with a band of high boundary layer stability behind the surface front leading to evaporation of layer cloud downstream of Dartmoor. This caused additional surface heating in the low-level tongue of high $\theta_{w}$ air.

The last is crucial, and demonstrates that the effect of orography can be more subtle than is usually expected. The timing of the passage of the front may also have been crucial. If it had passed earlier there might not have been sufficient surface heating through the cloud hole.

The above factors can be grouped according to their characteristic scale-the synoptic- or meso- $\alpha$-scale $(1$ and 2 ) or the meso- $\beta$ and $\gamma$ response of this to the surface forcing ( 3 and 4 ), with the possible proviso that the layer cloud, which is evaporated, is also a feature of the synoptic-scale flow. The model results show that a successful forecast relies on the accuracy of both, but also that, given a sufficiently accurate synoptic-scale forecast, the model is capable of responding sufficiently accurately to the surface forcing to yield an extremely accurate response in the absence of additional data assimilation at smaller scales. This might have been expected for relatively simple flow, but, in this case, the interaction of orography with clouds and hence surface fluxes all had to be sufficiently correct.

These results are encouraging for longer lead-time forecasts, as they show that accuracy at the synoptic or meso- $\alpha$ scale may be sufficient, in itself, to yield useful forecasts. It also highlights, however, that in monitoring forecasts, indicators such as cloud cover and systematic impacts on cloud cover from orography should be taken into account, as errors in these may have substantial knock-on effects. For the same reason, the impact of cloud in nowcasts should take greater emphasis, not only because of their direct role in precipitation, but also through less obvious indirect effects via the surface energy budget.

This study, in conjunction with others (Golding et al. 2005; Roberts 2008) provides some insight into the predictability of convective storms over the United Kingdom. It shows the importance of getting the meso- $\alpha$ scale correct even when running fine-resolution models that are capable of an accurate represent of more local 
scales. With the next stage in storm-resolving NWP likely to be a more ensemble approach there needs to be an emphasis (over maritime western Europe at least) on capturing the uncertainty in the meso- $\alpha$ scale (inherited from the coarser-resolution driving model) as well as the details of the physics and small-scale uncertainty.

Acknowledgments. This work was funded by the Met Office National Meteorology Programme (NMP). CSIP was funded by the Natural Environment Research Council and by the NMP. We wish to thank everyone who was involved in the CSIP observational programme. We thank Keith Browning and Brian Golding for useful comments and the anonymous reviewers for their comments that have lead to a significantly improved manuscript.

\section{REFERENCES}

Barker Schaaf, C., J. Wurman, and R. M. Banta, 1988: Thunderstormproducing terrain features. Bull. Amer. Meteor. Soc., 69, 272277.

Bennett, L. J., K. A. Browning, A. M. Blyth, D. J. Parker, and P. A. Clark, 2006: A review of the initiation of precipitating convection in the United Kingdom. Quart. J. Roy. Meteor. Soc., 132, 1001-1020.

Browning, K. A., and G. A. Monk, 1982: A simple model for the synoptic analysis of cold fronts. Quart. J. Roy. Meteor. Soc., 108, 435-452.

— tation structure along a cold front. Quart. J. Roy. Meteor. Soc., 122, 1845-1872.

— ject. Bull. Amer. Meteor. Soc., 88, 1939-1955.

Burt, S., 2005: The cloudburst upon Hendraburnick down: The Boscastle storm of August 2004. Weather, 60, 219-227.

Collier, C. G., 2007: Flash flood forecasting: What are the limits of predictability? Quart. J. Roy. Meteor. Soc., 133, 3-23.

Crook, A. N., and D. F. Tucker, 2005: Flow over heated terrain. Part I: Linear theory and idealized numerical simulations. Mon. Wea. Rev., 133, 2552-2564.

Cullen, M. J. P., T. Davies, M. H. Mawson, J. A. James, S. C. Coulter, and A. Malcolm, 1997: An overview of numerical methods for the next generation UK NWP and climate model numerical methods in atmospheric and ocean modelling. The Andre J. Robert Memorial Volume, C. A. Lin, R. Laprise, and H. Ritchie, Eds., Canadian Meteorological and Oceanographic Society, 425-444.

Davies, T., M. J. P. Cullen, A. J. Malcolm, M. H. Mawson, A. Staniforth, A. A. White, and N. Wood, 2005: A new dynamical core for the Met Office's global and regional modelling of the atmosphere. Quart. J. Roy. Meteor. Soc., 131, 1759-1782.

Done, J. M., C. A. Davis, and M. Weisman, 2004: The next generation of NWP: Explicit forecasts of convection using the weather research and forecasting (WRF) model. Atmos. Sci. Lett., 5, 110-117.

Essery, R., M. Best, and P. Cox, 2001: MOSES 2.2 Technical Documentation. Hadley Centre Tech. Rep. 30, Met Office Hadley Centre, 30 pp.
Golding, B., P. A. Clark, and B. May, 2005: The Boscastle Flood: Meteorological analysis of the conditions leading to flooding on 16 August 2004. Weather, 60, 230-235.

Gregory, D., and P. R. Rowntree, 1990: A mass flux convection scheme with representation of cloud ensemble characteristics and stability-dependent closure. Mon. Wea. Rev., 118, 14831506.

Hand, W. H., N. I. Fox, and C. G. Collier, 2004: A study of twentieth-century extreme rainfall events in the United Kingdom with implications for forecasting. Meteor. Appl., 11, $15-31$.

Hunt, J. C. R., A. Orr, J. W. Rottman, and R. Capon, 2004: Coriolis effects in mesoscale flows with sharp changes in surface conditions. Quart. J. Roy. Meteor. Soc., 130, 2703-2731.

Lean, H. W., P. A. Clark, M. Dixon, N. M. Roberts, A. Fitch, R. Forbes, and C. Halliwell, 2008: Characteristics of highresolution versions of the Met Office Unified Model for forecasting convection over the United Kingdom. Mon. Wea. Rev., 136, 3408-3424.

Lock, A. P., A. R. Brown, M. R. Bush, G. M. Martin, and R. N. B. Smith, 2000: A new boundary layer mixing scheme. Part I: Scheme description and single-column model tests. Mon. Wea. Rev., 128, 3187-3199.

Morcrette, C., H. W. Lean, K. A. Browning, J. Nicol, N. Roberts, P. A. Clark, A. Russell, and A. Blyth, 2007: Combination of mesoscale and synoptic mechanisms for triggering an isolated thunderstorm: Observational case study of CSIP IOP1. Mon. Wea. Rev., 135, 3728-3749.

Purdom, J. F. W. 1976: Some uses of high-resolution GOES imagery in the mesoscale forecasting of convection and its behavior. Mon. Wea. Rev., 104, 1474-1483.

Roberts, N. M., 2003: The impact of a change to the use of the convection scheme to high-resolution simulations of convective events. Met Office Tech. Rep. 407, 30 pp.

- 2008: Meteorological components in forecasts of extreme convective rainfall using $12-\mathrm{km}$ and $1-\mathrm{km}$ NWP models: A tale of two storms. Met Office R\&D Tech. Rep. 520, $58 \mathrm{pp}$.

- , and H. W. Lean, 2008: Scale-selective verification of rainfall accumulations from high-resolution forecasts of convective events. Mon. Wea. Rev., 136, 78-97.

Roeloffzen, J. C., W. D. Van den Berg, and J. Oerlemans, 1986: Frictional convergence at coastlines. Tellus, 38A, 397-411.

Romero, R., C. A. Doswell, and R. Riosalido, 2001: Observations and fine-grid simulations of a convective outbreak in northeastern Spain: Importance of diurnal forcing and convective cold pools. Mon. Wea. Rev., 129, 2157-2182.

Russell, A., G. Vaughan, E. G. Norton, C. J. Morcrette, K. A. Browning, and A. M. Blyth, 2008: Convective inhibition beneath an upper-level PV anomaly. Quart. J. Roy. Meteor. Soc., 134, 371-383.

Schwartz, C. S., and Coauthors, 2009: Next-day convectionallowing WRF model guidance: A second look at $2-\mathrm{km}$ versus 4-km grid spacing. Mon. Wea. Rev., in press.

Smith, S. A., 2004: Observations and simulations of the 8 November 1999 MAP mountain wave case. Quart. J. Roy. Meteor. Soc., 130, 1305-1325.

J. D. Doyle, A. Brown, and S. Webster, 2006: Sensitivity of resolved mountain drag to model resolution for MAP case studies. Quart. J. Roy. Meteor. Soc., 132, 1467-1487.

Smith, S. D., 1988: Coefficients for sea surface wind stress, heat flux and wind profiles as a function of wind speed and temperature. J. Geophys. Res., 93, 15 467-15 472. 
Vosper, S. B., 2004: Inversion effects on mountain lee waves. Quart. J. Roy. Meteor. Soc., 130, 1723-1748.

Webster, S., M. Uddstrom, H. Oliver, and S. Vosper, 2008: A high resolution modelling case study of a severe weather event over New Zealand. Atmos. Sci. Lett., 9, 119-128.

Weisman, M. L., W. C. Skamarock, and J. B. Klemp, 1997: The resolution dependence of explicitly modeled convective systems. Mon. Wea. Rev., 125, 527-548.
Wilson, D. R., and S. P. Ballard, 1999: A microphysically based precipitation scheme for the UK Meteorological Office Unified Model. Quart. J. Roy. Meteor. Soc., 125, $1607-$ 1636.

Wilson, J. W., B. Foote, A. Crook, J. C. Fankhauser, C. G. Wade, J. D. Tuttle, and C. K. Mueller, 1992: The role of boundarylayer convergence zones and horizontal rolls in the initiation of thunderstorms. Mon. Wea. Rev., 120, 1785- 1815. 